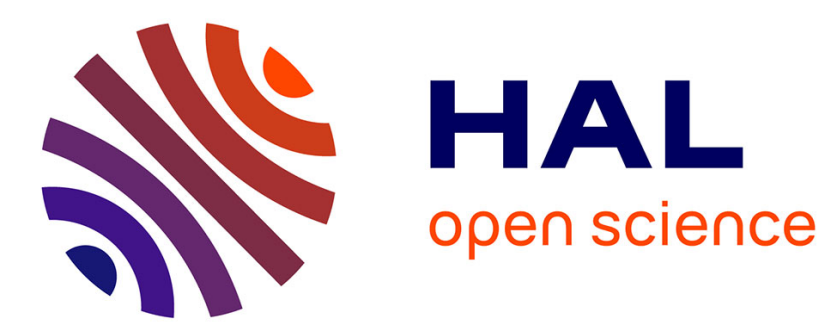

\title{
Low temperature electrochemical production of hydrogen: challenge in anode and cathode materials
} Sarra Knani, Teko Napporn

\section{To cite this version:}

Sarra Knani, Teko Napporn. Low temperature electrochemical production of hydrogen: challenge in anode and cathode materials. Current Trends and Future Developments on (Bio-) Membranes, Elsevier, pp.135-169, 2020, 10.1016/B978-0-12-817110-3.00005-9 . hal-03055734

\section{HAL Id: hal-03055734 https://hal.science/hal-03055734}

Submitted on 11 Dec 2020

HAL is a multi-disciplinary open access archive for the deposit and dissemination of scientific research documents, whether they are published or not. The documents may come from teaching and research institutions in France or abroad, or from public or private research centers.
L'archive ouverte pluridisciplinaire HAL, est destinée au dépôt et à la diffusion de documents scientifiques de niveau recherche, publiés ou non, émanant des établissements d'enseignement et de recherche français ou étrangers, des laboratoires publics ou privés. 


\title{
Low temperature electrochemical production of hydrogen: challenge in anode and cathode materials
}

\author{
Sarra Knani ${ }^{1}$ and Têko W. Napporn ${ }^{2}$
}

\author{
${ }^{1}$ Laboratoire de chimie des matériaux et catalyse, Département de chimie, Faculté des Sciences \\ de Tunis, Université Tunis El Manar, 2092 Tunis, Tunisia. \\ ${ }^{2}$ IC2MP UMR 7285 CNRS Université de Poitiers, 4 rue Michel Brunet B27 TSA 5110686073 \\ Poitiers Cedex 09, France
}

\begin{abstract}
Production of high pure hydrogen from water electrolysis requires the development of highly effective and robust electrocatalysts for both oxygen (OER) and hydrogen evolution (HER) reactions. For several years, the development of new catalytic materials with various morphology, structure and composition has attracted attention of the worldwide researchers. Their main goals were to reach an improvement in activity, selectivity and stability of the electrocatalysts with a minimum of cost. However, many articles published the dependency of these reactions to noble metals (e.g. Pt, Ru Ir). In this chapter, past findings and latest development of metal oxides and Pt-based materials as anode and cathode catalysts, respectively, are summarized. Furthermore, the role of morphology and electronic structure of the nanocatalysts is also discussed to understand the mechanistic basis of their electrocatalytic performances.
\end{abstract}

\subsection{Introduction}

The increase of energy demands and the scarcity of fossil resources with global warming caused by greenhouse gas emissions create the most urgent challenge of our century: the development of sustainable and clean energy sources. Hydrogen is a potential energy carrier which can be produced from various feed stocks [1]. Particularly, electrocatalytic technologies play a crucial role in energy supply field by converting an electrochemical energy from reactions to electricity. Water electrolysis is considered as the most promising way to produce clean 
hydrogen by using renewable energy devices (photovoltaic, wind energy, etc...) [2]. However, in water splitting reaction the two half reactions, oxygen evolution reaction (oxidation of $\mathrm{H}_{2} \mathrm{O}$ to $\mathrm{O}_{2}$ ) and hydrogen evolution reaction (reduction of $\mathrm{H}^{+}$to $\mathrm{H}_{2}$ ), are kinetically limited mainly the OER. Therefore, exploration of active, selective and stable electrocatalytic materials is prominent to catalyze both half reactions and to achieve sustainable energy supplies from hydrogen. The best electrocatalysts for both anodic and cathodic reactions should exhibit an ideal balance between binding and releasing of adsorbed reaction intermediates. The volcano plots investigated by Trasatti, S. [3, 4] demonstrated that Pt and $\mathrm{RuO}_{\mathrm{x}}$ are the most efficient catalysts for HER and OER, respectively [3-10]. The following chapter gives an insight on efficient electrocatalysts used for OER and HER with specific focus on the ways adopted to promote both mechanisms.

\subsection{Water splitting reactions}

The water splitting reaction (1) requires two half-cell reactions. HER on the cathodic side and OER on the anodic side.

$2 \mathrm{H}_{2} \mathrm{O} \rightarrow \mathrm{O}_{2}+2 \mathrm{H}_{2} \quad E^{\circ}=1.23$ V vs. $\mathrm{RHE}$

\subsubsection{The hydrogen evolution Reaction}

In acid medium, hydrogen evolution reaction may processes via two steps on various electrocatalysts. The first step is usually hydrogen adsorption on the catalyst's surface by a charge transfer (Volmer reaction) (equation 2). The second step can be two different reactions. One is the Tafel recombination reaction in which two adsorbed hydrogen atoms combine on the catalyst surface and evolve molecular hydrogen (equation 3). The other possible pathway is the electrochemical desorption step or Heyrovsky step (electrochemical desorption), where a proton reacts with an adsorbed hydrogen atom and an electron to form $\mathrm{H}_{2}$ (equation 4).

$$
\begin{array}{ll}
M+H^{+}+e^{-} \rightarrow M H_{a d s} & \text { Volmer equation } \\
M H_{\text {ads }}+M H_{\text {ads }} \rightarrow 2 M+H_{2} & \text { Tafel equation } \\
M H_{\text {ads }}+H^{+}+e^{-} \rightarrow M+H_{2} & \text { Heyrovsky equation }
\end{array}
$$

where $\mathrm{M}$ is an active metal site.

Depending on the electrocatalytic properties of the electrode materials, the HER occurs via the Volmer-Heyrovsky mechanism or Volmer-Tafel mechanism. 


\subsubsection{The oxygen evolution reaction}

Oxygen Evolution Reaction is more preferable in acidic condition owing to high ionic conductivity and fewer contaminants (e.g, carbonates in alkaline medium) [11].

OER is kinetically demanding and more complicated than HER. A generalized mechanism on oxide electrode materials has been proposed by Lodi et al. [12]:

the first step involves the formation of hydroxides from water molecules on an active surface site (S):

$\mathrm{M}+\mathrm{H}_{2} \mathrm{O} \rightarrow \mathrm{M}-\mathrm{OH}+\mathrm{H}^{+}+e^{-}$

Then, the stable intermediate undergoes an electrochemical oxidation:

$M-O H \rightarrow M-O+H^{+}+e^{-}$

$\mathrm{M}-\mathrm{OH}+\mathrm{M}-\mathrm{OH} \rightarrow \mathrm{M}-\mathrm{O}+\mathrm{M}+\mathrm{H}_{2} \mathrm{O}$

and in the last step $\mathrm{O}_{2}$ is produced:

$M-O+M-O \rightarrow O_{2}+2 M$

Other mechanism can be proposed [13] with the formation of a superoxide as intermediate and oxygen as final product. The first step consists of water dissociation:

$\mathrm{H}_{2} \mathrm{O} \leftrightarrow \mathrm{OH}_{\mathrm{ads}}+\mathrm{H}^{+}+\mathrm{e}^{-}$

$\mathrm{OH}_{\mathrm{ads}}$ is further oxidized to $\mathrm{O}_{\mathrm{ads}}$

$O H_{a d s} \leftrightarrow O_{a d s}+H^{+}+e^{-}$

Then, superoxide intermediates are formed

$\mathrm{H}_{2} \mathrm{O}+\mathrm{O}_{a d s} \leftrightarrow \mathrm{OOH}+\mathrm{H}^{+}+e^{-}$

Finally, the $\mathrm{O}_{2}$ evolution:

$O O H_{a d s} \leftrightarrow O_{2}+H^{+}+e^{-}$

\subsection{Kinetic parameters of HER and OER}


A huge number of possible catalysts, notably from transition metal can be made to enhance the hydrogen and oxygen evolution reactions rates. Two properties which play an important role for selecting the most efficient material for the corresponding electrochemical reaction are: the electrocatalytic activity of the catalyst and its long term-stability. In this section, we will resume briefly the main parameters recognized for evaluating and comparing the electrocatalytic activity of various HER or OER catalytic materials.

\subsubsection{Overpotential and onset potential}

Theoretically, an electrochemical reaction has a potential $\left(E_{\text {eq }}\right)$ which can be calculated from the Nernst equation. However, no reaction occurs at the value predicted from thermodynamics [14]. Indeed, at a material surface, the reaction occurs at a potential different from the theoretical value $\mathrm{E}_{\mathrm{eq}}$. Therefore, high potential $\mathrm{E}$ is required to initiate the reaction. At a defined current value, the difference between this potential $\mathrm{E}$ and theoretical value is called the overpotential (denoted by the symbol $\eta$ ) in the equation (13):

$\eta=E-E_{e q}$

In order to compare activity of different catalysts, the onset potential is also used. This latter refers to the smallest potential at which activity for the half - reaction under study starts [15]. The onset potential is often determined at a benchmark current density of 1 and $10 \mathrm{~mA} \mathrm{~cm}^{-2}$ geo for HER and OER, respectively.

\subsubsection{Tafel slope $(b)$ and exchange current density $(j o)$}

According to the Butler-Volmer model, the kinetic rates (current density, $\mathrm{j}$ ) is related with $\eta$ by the following equation (14) [6]:

$j=j_{0}\left[e^{\frac{(1-\alpha) n F \eta}{R T}}-e^{\frac{-(\alpha n F \eta)}{R T}}\right]$

where $j$ is the current density, $j_{0}$ is the exchange current density, $\eta$ is the overpotential, $\alpha$ is known as the charge transfer coefficient, $n$ is the number of electrons transferred (which is equal to 2 for HER and to 4 for OER), $R$ is the ideal gas constant, $T$ is the temperature and $F$ is the Faraday constant.

In the case of HER, at low overpotential $(|\eta|<5 \mathrm{mV})$, the Butler-Volmer equation can be simplified as follow: 
$j=j_{0} e^{\frac{n F}{R T} \eta}$

It indicated that the current density is linearly correlated with the overpotential in a narrow potential range near the equilibrium.

At high overpotential $(|\eta|>5 \mathrm{mV})$, the Butler-Volmer equation can be written as in the equation (16) and transformed to the form of Tafel equation (equation 17) [16]:

$j=j_{0} e^{\frac{-\alpha n F \eta}{R T}}$

$\eta=a+b \log j=\frac{2.3 R T}{\alpha n F} \log j_{0}-\frac{2.3 R T}{\alpha n F} \log j$

From the equation (17), it is possible to assess the kinetic parameters by plotting the overpotential $\eta$ as a function of $\log (j)$, universally known as Tafel plot [17]. The constant $b$, defined as Tafel slope, is related to the reaction mechanism of a catalyst and it is useful for evaluating the rate determining step (rds) of the reaction.

For HER, The Tafel slope values are $120 \mathrm{mV} \mathrm{dec}{ }^{-1}, 40 \mathrm{mV} \mathrm{dec}{ }^{-1}$ and $30 \mathrm{mV} \mathrm{dec}^{-1}$ for the Volmer, Heyrovsky and Tafel reactions, respectively [18].

In the case of OER, it is more complicated to determine the Tafel slope since the reaction involves four electrons giving rise to many possible pathways and a range of adsorbed intermediates (M-OH, Mo, MOOH etc...). Hence, in practice many Tafel regions may be observed. Obviously, two distinct linear regions is a common kinetic feature of the OER Tafel plots presented in the literature $[19,20]$. In acidic medium, the most Tafel plots values are 120 $\mathrm{mV} \mathrm{dec}{ }^{-1}$ when the first electron is the rate determining step and $60 \mathrm{mV} \mathrm{dec} \mathrm{de}^{-1}$ means that the first step could be followed by a second electron transfer with intermediate adsorption in agreement with the Temkin isotherm [20].

From the Tafel equation (17), it is also possible to determine another kinetic parameter, the exchange current density $\left(j_{0}\right)$. It is basically the spontaneous reaction rate at equilibrium potential. It reflects the intrinsic catalytic property of an electrocatalyst as well as the intrinsic rate of electron transfer between an analyte in solution and the electrode. It is possible to extract the exchange current density by the extrapolation of the respective linear Tafel region to $\eta=0$ V. However, this extrapolation is subject to relatively large uncertainties. For this reason, Seri 
[21] recently proposed a new technique allowing an accurate reading of Tafel slope and exchange current density. According to the author, a reliable Tafel slope (b), charge transfer coefficient $(\alpha)$ and exchange current density $\left(j_{0}\right)$ values are obtained after taking into account the physical resistance such as oxide film $\left(l_{C} / k_{C}\right)$ and solution resistance $\left(l_{S} / k_{s}\right)$ in the Tafel equation. To reach this issue, the polarization resistance $(h(j))$ was obtained by differentiating $E(j)$ curves. Then, $h(j)$ is plotted versus current density and a Tafel slope shape was obtained. The exact current exchange density was afterward determined by excluding the physical resistance parameters.

To realize an efficient hydrogen and oxygen evolution reaction, the electrocatalyst should obey the specific requirement such as low onset overpotential, small Tafel plot and large value of exchange current density $\left(j_{0}\right)$.

\subsubsection{Turnover Frequency (TOF)}

Most practical catalysts include many different types of surface sites, each with its inherent activity. Effectively, the active sites often have special local structures and stoichiometry, such as edges, corners or other defect sites. The geometric area of catalysts can be largely different from the effective active surface area due to their porosity or roughness. The exchange current density $(j o)$ is not an ideal metric for comparing catalytic activity of different materials since it does not provide the intrinsic activity of each catalytic site necessary for a fundamental understanding of the origins of the materials activity. In this perspective, the intrinsic catalyst activity per-site is measured by the turnover frequency. Practically, the TOF does not depend on how much metal is loaded onto a support or a reactor. Indeed, the measure of turnover frequency made reliable the comparison of rates measured on different catalysts.

In the field of heterogeneous catalysis, the Turnover Number (TON) first appeared to denote the number of converted reactant molecules per minute per catalytic site under defined reaction conditions [22]. Thereafter, the rate referred to the number of the catalytic site became known as the Turnover Frequency defined as the number of catalytic cycles occurring at the center per unit time representing a chemical reaction rate. The value of TOF is closely relative to the intrinsic per-site activity of a catalyst. However, the measurement of turnover frequency seems to be complicated since the determination of a reaction rate and the counting of active sites are very difficult tasks. Despite these experimental difficulties there are many advantages by determining TOF. In his excellent review, Boudart, M. [23] gave five advantages of measuring the turnover frequency. First of all, according to him, the determination of TOF could be 
reproducible by different laboratories if the methods and conditions of measurements of the rate are fully described. Thereby, it could be possible to compare between different catalysts. Moreover, the value of TOF, even if it is approximate since the approximations made in counting active sites, can indicate whether the material is a catalyst or a simple reagent. Other advantages cited by Boudart are useful in practice and theory. He reported that the advantages of determining TOF on catalysts with many different types of active sites can provide a clear experimental test of the absence of artifacts in the rate measurements as a result of heat and mass transfer. Also it can indicate the importance and no importance of crystalline anisotropy especially when the catalytic material presents different crystallographic planes and clusters with different sizes. Finally, measurement of TOF is a reliable way to compare the assessed potential of new catalytic materials and others in current use.

For HER and OER, TOF per active sites is defined as the number of reactants evolved on an active site per unit of time (e.g. in s ${ }^{-1}$ ). The higher is the TOF, the better is the catalyst. Assuming the cathodic current is entirely attributed to HER: the equation (18) is used to calculate TOF [24]:

$T O F=\frac{I N_{A}}{A n F \Gamma}$

where $I$ is the current density, $N_{A}$ is the Avogadro constant, $A$ is the geometrical surface area, $n$ is the stoichiometric number of electrons consumed in the electrode reaction (i.e. $n=2$ for the HER and $\mathrm{n}=4$ for the OER) and $\Gamma$ is the surface or total concentration of catalyst in terms of number of atoms.

The turnover frequency can be computed by different ways [25-27]. The only critical issue originates from the precision in measuring the surface concentration of the atoms. For instance, $\mathrm{Ma}$ et al. [28] calculated the turnover frequency for molybdenum carbide $\left(\mathrm{Mo}_{2} \mathrm{C}\right)$ using the average particle diameter of the catalysts or by taking the measured surface area from BET data. However, the uncertainty in the estimation of surface area leads to two different values of TOF that differ by orders of magnitude. The authors attributed the difference to the agglomeration of $\mathrm{Mo}_{2} \mathrm{C}$ nanoparticles which reduces the surface area that can be afforded by $\mathrm{N}_{2}$ physisorption method. The method which uses the electrochemical cyclic voltammetry technique and the electrochemically active surface area (EASA), is the most used [29-32]. Nevertheless, this latter may cause potential error when there is more than one element in the catalysts or if the catalyst is not fully activated. Hence, it is more convenient to adopt a method appropriate to the nature 
of the catalyst. Other than, the comparison between TOFs for different catalysts is meaningful when the value is taken at the same overpotential.

\subsubsection{Mass and specific activities}

Since, the uncertainties related to the determination of the current exchange density and Tafel slope, alternative ways to define catalyst activity in an electrochemical reaction have emerged. These include mass activity and specific activity.

\subsubsection{Mass activity}

According to Bregoli [33], the term mass activity, $A_{(g)}$, is used to define the current at a given overvoltage per unit of mass of catalyst. This term is expressed by amperes per $\mathrm{g}(\mathrm{A} / \mathrm{g})$ given by the equation (19) [34]:

$A_{(g)}=\frac{j}{W}$

where $A_{(g)}$ is the mass activity of a catalyst, $j$ is the current density in $\mathrm{A} \mathrm{cm}^{-2}$ at a given potential and $W$ is the catalyst loading, normalized for the geometrical area of the electrode, in $\mathrm{mg} \mathrm{cm}^{-2}$. More accurate methods are used to determine the catalyst loading by suitable analytical methods (e.g. ICP). Fabbri et al. [35] considered that loading -normalized current density is lesser affected by experimental inaccuracies than the other activity parameters. However, $A_{(g)}$ is not a credible parameter for evaluating the intrinsic activity of the material because of the many disadvantages cited above: it does not allow a fair comparison between catalysts with different particle size/ morphology (e.g. rod, spherical and wire) and/ or molecular mass. Otherwise, it does not permit a direct comparison with the theoretical activity generally normalized by active sites (e.g TOF).

\subsubsection{2. $\quad$ Specific activity}

The current normalized by the electrochemical active surface area (EASA) or by specific surface area (obtained from the BET (Brunauer-Emmett-Teller) measurement) is the specific activity. It is is defined as:

specific activity $=\frac{j}{s_{r}}\left(m A \mathrm{~cm}^{-2}\right)$

where $S_{r}$ is the accessible/ electrochemical active surface area of the catalyst in $\mathrm{cm}^{2}$ (it is better to consider $1 \mathrm{~g}$ of catalyst to facilitate the comparison). An excellent discussion of the effects 
of catalyst surface are on specific activity is made by Sattler and P.N. Ross [36]. The authors showed the strong relationship between specific activity and Pt surface area and its crystallites size. According to them, the specific activity decreases as platinum crystallites increase in accessible surface area. The electrochemical active surface area can be obtained from by integrating the hydrogen desorption zone or the anodic current of the CO peak [37].

Normalizing the current by the specific surface area determined by BET (used often in heterogeneous catalysis) could be also used to evaluate catalytic activity of many materials. However, this method is not experimentally accurate due to the fact that the sites in the BET surface area are not all electrochemically active.

\subsection{Electrocatalytic stability of materials for HER and OER}

The stability is a critical aspect in the development of electrocatalysts. Stability in its broadest sense covers any aspects of change of the material properties over a long time scale and under experimental conditions. There is hence an enormous need for reliable approaches to probe whole design life of the catalyst so as to predict its long term performance. Different approaches were followed to evaluate the stability of the electrodes during the electrochemical reaction process [38-42].

Accelerated Durability Test (ADT) is a commonly used method to estimate lifetime of electrode. This test is realized by subjecting the electrocatalysts between specific potential limits to several thousands of cycles at high scan rate. The onset potential and the overpotential at defined current density $10 \mathrm{~mA} \mathrm{~cm}^{-2}$ are valuable information which can be deduced after ADT studies and used as indicative parameters of a catalyst stability. It is important to highlight that a smaller increase in overpotential indicating a higher stability. Other effective diagnostic were used such as chronopotentiometry or even chronoamperometry, i.e. holding the electrode material at a fixed current density (10 $\mathrm{mA} \mathrm{cm}_{\text {geo }}^{-2}$ ) while measuring the operating potential as a function of time, or at a fixed potential, respectively. And both of them are examined for duration of minutes to hours. Nevertheless, a stable current density (e.g. $10 \mathrm{~mA} \mathrm{~cm}^{-2}$ ) by chronoamperometry or a negligible increase in overpotential by chronopotentiometry, for more than 12 hours for both cases, is enough to admit an efficient electrocatalyst for HER or OER.

\subsection{Platinum based electrocatalysts for HER}


As mentioned above, platinum is the most performant metal for HER in acidic medium, owing to its near-zero overpotential at $1 \mathrm{~mA} \mathrm{~cm}^{-2}$. For this reason, it is frequently used to benchmark the activity of other HER electrocatalysts. Therefore, consecutive studies have been mainly made to establish a relationship between the surface and structure properties of the Pt in order to maximize the rate of hydrogen evolution reaction and to understand the kinetic dependence on hydrogen binding energy.

\subsubsection{HER on Pt(hkl) single crystals in acidic electrolyte}

Hydrogen adsorption on platinum single crystal surfaces is considered as one of the first adsorption system studied date back several years. Since 1965s, pioneering work of Will [43] highlighted the feasibility of hydrogen adsorption on different faces (111), (110) and (100) of platinum single crystal electrodes. On the other hand, the adsorption isotherms of hydrogen plotted for the three crystal faces at constant hydrogen pressure, showed that the degree of coverage decrease distinctly in the following order: $\left(\begin{array}{lll}1 & 0 & 0\end{array}\right)>\left(\begin{array}{lll}1 & 1 & 1\end{array}\right)>\left(\begin{array}{lll}1 & 1 & 0\end{array}\right)$. Consequently, from this study it could be established that $\mathrm{HER}$ on $\operatorname{Pt}(h k l)$ is a structure sensitive reaction. However, the first investigation of hydrogen evolution reaction on $\mathrm{Pt}(h k l)$ electrode demonstrated that the kinetics rate of the reaction is not sensitive to the crystallography of the surface $[44,45]$. Indeed, Tafel slopes and exchange current density calculated for each face, do not change regardless the Pt crystal planes. Nonetheless, further works have proved that the HER is indeed a structure sensitive-reaction [46-49]. Marković et al. [46] showed for the first time that the exchange current density, at a fixed temperature, increases in the order (110) > $(100)>(111)$ with the value found on (110) is three time higher than that on (111). Moreover, according to these authors the activation energies for the HER increases in the same sequence as the order of activity $E_{a}(110)<E_{a}(100)<E_{a}(111)$. The key factors that make the HER energy activation different from one platinum crystal plane to another, is the role of underpotential/ overpotential deposited hydrogen $\left(\mathrm{H}_{\mathrm{upd}} / \mathrm{H}_{\mathrm{opd}}\right)$ and the fractional coverage of hydrogen on active sites [9]. In fact, surface X-ray scattering experiments (SXS) revealed that the interaction between $\mathrm{H}_{\text {upd }}$ and $\mathrm{Pt}(111)$ is very week and $\mathrm{H}_{\text {upd }}$ is adsorbed onto the Pt (111). In the case of $\mathrm{Pt}(100)$ the situation is completely opposite. The SXS experiments displayed a strong interaction between $\mathrm{Pt}(100)$ and $\mathrm{H}_{\text {upd. }}$. It seems that this latter form a monolayer and sits in deeper potential wells, thus $\mathrm{H}_{\text {upd }}$ seems to be in the surface rather than on the surface. The mechanism of HER on $\mathrm{Pt}(100)$ proceeds via Heyrovsky- Volmer sequence with the Heyrovsky step as the $r d s$. In the case of $\mathrm{Pt}(110)$, it seems that most of the $\mathrm{H}_{\text {upd }}$ are below the surface (i.e. subsurface hydrogen), causing expansion of the top most platinum atoms which facilitates $\mathrm{H}_{2}$ 
adsorption and bond breaking/or making to form $\mathrm{H}_{\mathrm{opd}}$. At least it is obvious that HER on $\mathrm{Pt}(110)$ is controlled by the interaction between $\mathrm{H}_{\text {upd }}$ and $\mathrm{H}_{\mathrm{opd}}$, whose adsorption energy is strongly structure-sensitive.

Concerning mechanism of HER on Pt(110) Marković et al. [46] showed that the reaction follows Tafel - Volmer sequence with Tafel step as rds. The studies of Barber et al. [47] emphasize the surface-geometry dependence of the HER at various platinum surfaces, in acidic medium. And according to them, this relationship was obscured, in earlier works, by the $\mathrm{H}_{2}$ diffusion effect. For this reason, rotation rate methods in combination with electrochemical impedance spectroscopy (EIS) measurements were conducted to separate the kinetic and diffusive influences of HER on $\operatorname{Pt}(h k l)$ crystal surfaces and then a quantitative analysis of the electrode kinetics and Pt surface geometry could occurs. The order of activity, derived from the rate constants, reported by Barber et al. [47] is slightly different from one given by Marković et al. [46] i.e. $(100)<(111)<(110)$ in $0.5 \mathrm{M} \mathrm{H}_{2} \mathrm{SO}_{4}$. The geometric models that appear to rationalize the results of HER on different platinum crystal planes are first of all differences in $\Delta \mathrm{H}_{\mathrm{ads}}$ for overpotential deposition of $\mathrm{H}$, as cited by Marković et al. [46], and secondly, the number density and interatomic distance of nearest neighboring active sites for $\mathrm{H}_{\mathrm{opd}}$ necessary for $\mathrm{H}+\mathrm{H}$ combination to increase the overall reaction kinetics.

More recently, scanning tunneling microscopy (STM) has been used in order to establish the complete structure-rate kinetics relationships for the HER on Pt single crystal surfaces [50]. Their investigations revealed that the surface is formed by a flat terrace covered by few steps a Pt ad-islands with monoatomic height. For Pt(100), ad-islands with square shapes and ordered defects are clearly evidenced. However, the surface morphology of $\operatorname{Pt}(110)$ is well defined as evidenced by the STM images even after the HER measurements. The degree of activity was found to increase in the following order: $(110)>(100)>(111)$. Importantly, it was found that the kinetic rate of hydrogen evolution is proportional to the density of structural defects. These authors showed also the influence of the $\mathrm{pH}$ on the kinetic rates of the HER. It seems that the low-coordinated Pt atoms have a significant effect on the $r d s$ of the HER in alkaline solutions due to more facile dissociative adsorption of water. Within the limited scope of this report, it will not be possible to review all effect of $\mathrm{pH}$ on the structure surface of the Pt electrodes.

\subsubsection{HER on platinum nanoparticles}

Platinum polycrystalline surface shows a promising activity towards HER, with small Tafel plot and high exchange current density. However, the high cost and low abundance of the Pt 
hindered its widespread use for electrochemical production of hydrogen. Thus, several attempts aiming to improve the cost effectiveness without compromising the activity of the system have been made. One of the commonly pursued approaches is the increasing of platinum mass activity by nanostructuring. Obviously, several studies in the field of electrocatalysis, have shown the beneficial effect of the Pt nanoparticles (NPs), with controllable size and shape [5156]. However, compared to ideal surface, the NPs pose a challenge since symmetry-distinct adsorbate interactions have to be considered, while they possess a large number of adsorption site types (different faces, edge, and corner). Unfortunately, the observations of surface structure and nanoparticle size effects of platinum for HER are scarce [57, 58]. On the other hand, the literature contains conflicting reports about the effect of particle size. For instance, Takasu et al. [52] highlighted the increasing of the specific activity of platinum nanoparticles upon reducing the particle diameter, which is in agreement with the study of Antoine et al. [59] using a gas diffusion electrode half-cell to increase $\mathrm{H}_{2}$ mass transport. However, more recently Durst et al. showed the independency of the Pt NPs activity on the particle size. Clearly, the elucidation of the trend of the HER with respect to the Pt particles size and structure cannot be obtained only by using electrochemical techniques (cyclic voltammetry, rotating disk electrode, etc...).Thus far, it seems difficult to identify the nature of adsorbed intermediates, the structure of adsorbing layers, the surface structure effects of Pt nanoparticles for HER and so on [60-62]. Thus, the combination of electrochemical methods with theoretical study is mandatory for establishing particle size - catalytic activity relationships. It has been pointed out that the coupling of Density Functional Theory (DFT) with theoretical modeling should provide information on the structure dependence of $\mathrm{Pt}(111)$ to the different mechanism steps and their activation barriers in the HER [63]. Later, Yang et al. [64] combined DFT calculation with microkinetic modeling and detailed the nature of the reactive site and their coverage in order to understand surface structure and the PtNPs size effects on specific kinetics of HER. The authors showed the adsorption isotherm for $\mathrm{H}$ atom on different Pt surfaces. From the DFT calculation, they revealed that $\mathrm{H}$ coverage reaches about $2 / 3$ monolayers $(\mathrm{ML})\left(1 \mathrm{ML}=1 \mathrm{H}_{\mathrm{ads}}\right.$ per $\left.\mathrm{Pt}\right)$ on $\mathrm{Pt}(111)$ and it is predominantly adsorbed on the 3 -fold face-centered cubic (fcc) (fcc hollow sites). For coverage above about 0.2 ML, it was found that $\operatorname{Pt}(100)$ and $\operatorname{Pt}(110)$ surfaces can bind more than $1 \mathrm{ML}$ of $\mathrm{H}$ atoms at the equilibrium. The $\mathrm{H}$ atoms preferred to be adsorbed at the 2-fold bridge sites on $\mathrm{Pt}(100)$ and at the short bridges sites between two adjacent Pt atoms in the top atom rows on $\mathrm{Pt}(110)$. On the other hand, the researchers plotted theoretical values of $\left(j_{0}\right)$ against surface coverage of $\mathrm{H}$ adatoms at the equilibrium potential $\left(\theta_{0}\right)$ in order to compare the $j_{0}$ values of different Pt crystal faces to the Pt nanoparticles. The volcano plot 
obtained lets the prediction that facets sites are more catalytically active than edge surface. According to the authors, such behavior is due to the absence of some adsorption sites at nanoparticle edges, e.g. the long bridge sites on $\mathrm{Pt}(110)$ surface. Moreover, the dependency of surface atom fraction on platinum particle diameter was investigated. In short, it seems that the fraction of the (111) and (100) facet atoms increases if the NPs are larger, unlike the fraction of the edge atoms. So, when the ratio of facet to edge sites increases, the adverse size effect of small platinum nanoparticles will be observed.

Another study carried out by Tan et al. [65] aims to investigate the origin of particle size effects of Pt for the HER. Considering that the Pt particles are cubo-octohedra [66], the authors assumed that atom rows on the bridge and (100) facets are the most active sites for the HER. These latter contribute by $75 \%$ of the platinum nanoparticles activity contrary to the edge sites which were found inactive for the HER. The specific activity $\left(j_{0}\right)$ was found to increase for larger particles while mass activity increases below $2.2 \mathrm{~nm}$ but it decreases thereafter. As predicted the contribution of edge sites does not affect both trends. Importantly, the activation barriers $\left(E_{a}\right)$ of $\mathrm{H}_{2}$ desorption was considerably affected by the particle size. The increase observed, for mass activity, in the range of 1-2.2 nm suggests that the lowest $E_{a}$ barriers founded for (100) facet sites is owing to the increase of the particle size accompanied by the decrease in the fraction of edge atoms on the Pt nanoparticles surface. Unfortunately, this study does not elucidate the relationship between specific activities of larger particles and activate barriers but it could not deny the sensitivity of the adsorbed hydrogen intermediates to the particle size and the previous prediction of the adverse size effect of the Pt NPs for HER.

\subsubsection{HER on Supported platinum nanoparticles}

Apart from structure and morphology, the support material plays a crucial role on the efficiency of metal nanoparticle catalysts. Effectively, the substrate should be characterized by a high electrical conductivity and long corrosion resistivity so that the electrocatalysts demonstrate stability and long term durability under operating conditions. In addition, a support material with high surface area is mandatory to achieve the best degree of metal dispersion with low loading, especially, when using expensive metals such as Pt.

Carbon is the most common support material for various electrochemical reactions [67-70], however its oxidation under reaction conditions induces the damage of Pt-carbon contact resulting in a loss of active sites [71]. For this reason, many researchers focus on the development of new materials support with chemical and physical properties similar to that of carbon. Nevertheless, other carbon species may be better supports for Pt nanoparticles. Platinum NPs deposited onto carbonaceous materials, such as Multi walled carbon nanotubes 
[72], graphene oxide [73] and carbon nanofibers [74], appeared recently in the literature and they showed excellent electrocatalytic activity for HER in acidic medium.

It has been also reported that oxide materials could be a promising substrate for the Pt NPs. Roy et al. [75] described a procedure to elaborate PtNPs decorated oxide nanocomposite $\left(\mathrm{TiO}_{2}\right.$ $\mathrm{N}-\mathrm{rGO}$ ) and they demonstrate the effectiveness of such system to improve platinum activity for HER. According to the authors, such performance may be originated from the synergetic effect between Ti (III), N-rGO and PtNPs. In fact, the presence of Ti(III) state improves conductivity and protonation which facilitate the HER process. N-rGO promotes the charge transfer from electrode to catalyst surface. And both of these factors lead to an increase in the HER activity. In the same strategy, the study carried out by Khdary et al. [76] on silica supported platinum nanoparticles revealed high activity and long term stability of PtNPs-S for HER. The specific activity of this catalyst was found higher than that $\mathrm{Pt} / \mathrm{C}$ and its counterparts. Table.1 compares the electrocatalytic performance of various supported Pt NPs for HER.

\section{Table 1. Comparison of the activity of different platinum supported electrocatalysts for HER.}

Conducting polymers as platinum supporting materials have raised a great deal of scientific interest [77-79]. It has been found that this approach is beneficial to enhance HER process. In fact, porous material [80-84] such as conducting polymers are characterized by a large specific surface area, high electrical conductivity and structural stability [85] essential for the improvement of Pt NPs electrocatalytic activity and for the decrease of the catalyst costs. Kao et al. [77] have demonstrated that poly (vinylacetic acid) doped with platinum (Pt-PVAA) has an electrocatalytic activity similar to that of smooth Pt in sulfuric acid media. The exchange current density obtained for Pt-PVAA was in the range of $10 \mathrm{~mA} \mathrm{~cm}^{-2}$ to $50 \mathrm{~mA} \mathrm{~cm}{ }^{-2}$ for Pt loading of 0.25 to $25 \mu \mathrm{g} \mathrm{cm}^{-2}$ and the overpotential was decreased by ca. $600 \mathrm{mV}$. Moreover, they demonstrated the high stability of the Pt-PVAA for more than 400 hours without any particle degradation or aggregation during $\mathrm{H}_{2}$ generation unlike $\mathrm{Pt}$ cathode materials.

The Polyaniline-Chitosan (PAni-Chi) composite modified with nanosized Pt particles was found to be very active for hydrogen evolution reaction and could be a promising alternative to the usual electrocatalysts [78]. PAni-Chi/Pt is characterized by an exchange current density of ca. $10.76 \mathrm{~mA} \mathrm{~cm}^{-2}$ and a Tafel slope of $121 \mathrm{mV} \mathrm{dec}^{-1}$ which suggests that the HER proceeds via the Volmer-Heyrovsky mechanism where the rate is controlled by the Volmer Step. It has been also reported that the onset potential of HER shifts positively to $-0.5 \mathrm{~V}$ vs. $\mathrm{Ag} / \mathrm{AgCl}$ at 
low overpotential. However, the thickness of the composite film plays a crucial role to improve the catalyst performance. It was found that the composite film obtained after 30 cycles of the PAni-Chi possesses the best chemical linkage between PAni-Chi. The high electrocatalytic activity observed with PAni-Chi/Pt (30 cycles) may be connected to the rapid charge transfer between the composite film and $\mathrm{H}^{+}$strongly adsorbed on $\mathrm{Pt}$ nanoparticles. In addition, it was found that this material exhibits a long term electrochemical stability while keeping high activity even after 1000 cycles.

Another very active polymer based Pt catalysts towards hydrogen evolution was investigated by Chakrabartty et al. [79]. Poly( $\alpha$-terthiophene)-hybrid material could be prepared by chemical and electrochemical methods [86, 87]. Herein, Poly( $\alpha$-terthiophene)-Pt was prepared by the photochemical synthesis method using sun lamp of $125 \mathrm{~W}$. The hybrid electrocatalyst showed electrocatalytic performance better than $\mathrm{Pt} / \mathrm{C}$. Poly( $\alpha$-terthiophene)-Pt reaches current density of $10 \mathrm{~mA} \mathrm{~cm}{ }^{-2}$ at very low overpotential (ca. $67 \mathrm{mV}$ vs. RHE) with $8.55 \mu \mathrm{g} \mathrm{cm}^{-2}$ platinum amount, 6.6 times less than Pt/C. Furthermore, the onset potential of the HER (-8 mV vs. RHE) was found close to that of the reference catalyst. Two low Tafel slopes were obtained for Poly( $\alpha$-terthiophene)-Pt (37 mV dec $\left.{ }^{-1}\right)$ and Pt/C (31 mV dec $\left.{ }^{-1}\right)$ and such small slopes may be attributed to the high $\mathrm{H}_{\text {ads }}$ coverage $\left(\theta_{\mathrm{H}} \approx 1\right)$. It is also possible to assume that HER proceeds via Volmer-Tafel mechanism. The exchange current density ( $j o$ ) of Poly( $\alpha$-terthiophene)-Pt $\left(0.28 \mathrm{~mA} \mathrm{~cm}^{-2}\right)$ was slightly lower as compared to $\mathrm{Pt} / \mathrm{C}\left(0.367 \mathrm{~mA} \mathrm{~cm}^{-2}\right)$ but the hybrid material is able to retains its activity even after 5 hours of operation or 1000 continuous potential scans. According to the authors, this interesting electrocatalytic efficiency is due to the high dispersion of Pt nanoparticles on the polymer support which favors the electron transfer kinetics and facilitates the access of the electrolyte. Not to mention the good electrical conductivity and the mechanical stability of the polymer.

\subsubsection{HER on Platinum alloys}

Development of platinum based materials seems to be recently an efficient way in boosting $\mathrm{Pt}$ catalysts activity towards HER and to overcome the problems of the high cost and low abundance of platinum metal. Previous studies conducted by Kitchin et al. [88] proved the importance of the bimetallic systems to change adsorption energies of different adsorbates on catalytic sites and corresponding chemical reactivity. As reported, strain (i.e. the difference in the average bond length between the two metal atoms) and ligand (i.e. the bonding interaction between $d$ orbitals of both atoms) combined effects lead to a change in electronic structure (d- 
band width / center) and surface chemical properties with bimetallic systems. Indeed, the dissociative adsorption energy of hydrogen could rise or drop as a function of d-band center. So, if there is a tensile stress and strong binding interaction between both atoms resulting in a broadening of the $\mathrm{d}$ band, a decrease of the dissociative adsorption energy of $\mathrm{H}_{2}$ is observed. However, when the ligand effect is the weakest a narrowing of the $\mathrm{d}$ band is obtained with an increasing of the adsorption energy.

The elaboration method has been reported to have an influence on the factors (geometric and ligand effects) controlling the catalytic activity of Pt-based materials. Several preparation procedures, such as, chemical reduction, dealloyed method, chemical vapor deposition are among methods used to elaborate pluri-metallic platinum based catalysts as presented in Table 2.

\section{Table.2. Summary tables of the various adopted elaboration methods and the resulting characteristic of the Pt-based catalysts.}

A RuPt NP/ordered mesoporous carbon (OMC) film has been prepared using a dip-coating method by Bernsmeier et al. [89]. The Pt and Ru metal loadings were 4.3 and 0.83 wt \%, respectively. In general, the preparation route offers the properties of a good catalyst for hydrogen evolution reaction. The support is characterized by a high specific BET surface area $\left(1105 \mathrm{~m}^{2} \mathrm{~g}^{-1}\right)$ and conductivity (800 $\left.\mathrm{S} \mathrm{cm}^{-1}\right)$ in comparison with other carbon supports [95-98]. Other than, STEM-EDX analysis evidenced that active phase is composed of bimetallic RuPt alloy well dispersed on the mesoporous support with small particle size (Table. 2). Pt nanoparticles (NPs)/OMC based electrodes showed low Tafel slope of about $38 \mathrm{mV} \mathrm{dec}^{-1}$ while $\mathrm{Ru} / \mathrm{OMC}$ exhibits a Tafel slope of $75 \mathrm{mV} \mathrm{dec}^{-1}$. The difference in the Tafel slope values clearly indicates the importance of platinum presences in the electrocatalysis of HER. According to the authors, a $38 \mathrm{mV} \mathrm{dec}{ }^{-1}$ Tafel slope indicates a Volmer-Heyrovsky mechanism with electrochemical desorption (Heyrovsky reaction) as rate determining step. Furthermore, RuPt NPs/OMC showed an exchange current density of $1.39 \mathrm{~mA} \mathrm{~cm}^{-2}$ higher than its counterparts $\left(\mathrm{Pt} / \mathrm{OMC} \sim 1.2 \mathrm{~mA} \mathrm{~cm}{ }^{-2}\right.$ and $\mathrm{Ru} / \mathrm{OMC} \sim 0.1 \mathrm{~mA} \mathrm{~cm}^{-2}$ ) and a significant stability confirmed by cyclic voltammetry. Even after, a continuous potential cycling between -50 to $-250 \mathrm{mV}$ vs. RHE at a scan rate of $20 \mathrm{mV} \mathrm{s}^{-1}$, the cycles exhibit a negligible loss of the current response. The authors attributed the superior electrocatalytic activity of 
RuPt NPs / OMC essentially to two effects: Pt surface enrichment, owing to Ru dissolution [99], and to the strong interaction between platinum and ruthenium which prevents $\mathrm{Pt}$ dissolution. According to the authors, both of these effects promote weakening of the Pt-H bond strength. After that, the authors added that, physical properties of the OMC (high conductivity and porosity) and the homogenous morphology of RuPt/OMC helped a lot to improve electron and mass transportation which further contributed to the increasing of RuPt/OMC performance over Pt/C.

Shen et al. [92] investigated the effect of Pt addition (loading ranging from 1.4 to $6.8 \mathrm{wt} \%$ ) to Ag catalysts supported on Silicon nanowires (SiNW) on HER. Recently, Ag has attracted great interest in the Pt bimetallic systems [100-103]. Using the Pt-Ag as electrocatalysts seems to be a good way to reduce the cost of the materials since the lower price of Ag. Additionally, the lattice parameter of platinum and silver is very close, $0.3923 \mathrm{~nm}$ and $0.4090 \mathrm{~nm}$ respectively [100], which give rise more stability to the bimetallic system and could prevent noble metals dissolution especially in acidic medium [104]. Pt-Ag/SiNW composites were elaborated with different Pt ratios (Pt:Ag were 1.4: 21.8; 4.1:21.5; 6.8:21.1 wt \%). It was found that Pt addition from 1.4 to $4 \mathrm{wt} \%$ promotes the kinetics of the HER, whereas it decreases for higher Pt contents. The best catalytic behavior as well as the most stable material was evidenced with the

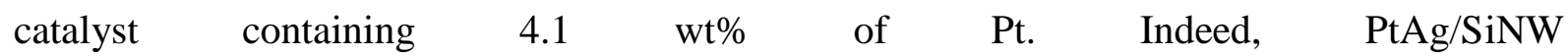
(4.1: $21.5 \mathrm{wt} \%$ ) required an overpotential of $135 \mathrm{mV}$ to attain $10 \mathrm{~mA} \mathrm{~cm}{ }^{-2}$ of current density and it exhibits a Tafel slope $(b)$ of $70 \mathrm{mV} \mathrm{s}^{-1}$, which is lower than its counterpart. The value of $b$ reveals that HER follows Volmer-Heyrovsky mechanism. Moreover, the calculated TOF was found $6.3 \mathrm{~s}^{-1}$ at $-0.2 \mathrm{~V}$ vs. RHE a value which is 2.7 times higher than that of commercial $\mathrm{Pt} / \mathrm{C}$ (40 wt \%). Meanwhile, a study carried out by Liu et al. [94] showed the possibility to improve the electrocatalytic activity of PtAg nanoparticles towards HER. PtAg nanoflowers (NFs) supported onto reduced graphene oxide ( $\mathrm{rGO}$ ) was synthesized by one-pot aqueous fabrication. The obtained PtAgNFs/rGO exhibits overpotential about $55 \mathrm{mV}$ vs. RHE at $10 \mathrm{~mA} \mathrm{~cm}{ }^{-2}$, and Tafel plot in the range of $31 \mathrm{mV} \mathrm{dec}^{-1}$. By comparison with Pt/C and Pt NPs/rGO, the durability studied by chronoamperometry at $-109 \mathrm{mV}$, is more significant with PtAgNFs/rGO during 10.000 seconds. The catalytic activity enhancement of the obtained material could be attributed to the porous morphology of PtAgNFs which promoting the enlargement of the electrochemical active surface area (EASA), thus preventing nanoparticles agglomerations. Furthermore, the incorporation of $\mathrm{Ag}$ provides additional stability to Pt owing to the synergetic effects between the two metals. It has been known that the addition of Ni to Pt boosts the sluggish kinetics of 
HER and reduces the overpotential. Huang et al. [90] conducted a detailed investigation on the electrochemical activity of unsupported PtNi nanodentrites (NDs) for HER in acidic medium. The sample was elaborated in oleylamine (OAm) by a one pot solvothermal method. The results indicate that the EASA of PtNi NDs $\left(41.31 \mathrm{~m}^{2} \mathrm{~g}^{-1}\right)$ is significantly larger than that of PtNi nanocrystals (NCs) $\left(27.66 \mathrm{~m}^{2} \mathrm{~g}^{-1}\right)$. Furthermore, the onset potential and the overpotential at 10 $\mathrm{mA} \mathrm{cm}{ }^{-2}$ of PtNi NDs were found close to Pt/C material but more promising than that of PtNi NCs. Additionnaly, PtNi NDs displayed the lowest Tafel slope value implying a faster electron transfer rate. Concerning its stability studied with ADT it was evidenced that, after 1000 cycles sweeping, there is no changes of the onset potential. The durability tests carried out by chronoamperometry showed a negligible decline of the current density of PtNi NDs (1.12\%) after 10.000 seconds contrary to PtNi NCs and Pt/C whose showed a higher decline of $7.97 \%$ and $3.06 \%$, respectively. The promotional activity and stability of PtNi NDs is due to its outstanding synergetic effect between both metals which contributes to form the $\mathrm{Ni}-\mathrm{H}$ bonds and thus accelerating the hydrolytic dissociation. Moreover, the authors believe that the protonation of $-\mathrm{NH}_{2}$ groups on the surface of the $\mathrm{PtNi}$ NDs increases the local $\mathrm{H}^{+}$concentration on the electrolyte/electrode interface which could improves the HER activity in acidic environment. These interesting studies provide a new insight on the role of morphological factors to enhance the catalytic performance of any material.

In addition to the $\mathrm{Pt}$ - bimetallic electrocatalysts, many studies have been reported on the use of more complex catalytic system with the main objectives of reducing platinum utilization and enhancing HER kinetics. Interesting results were obtained with PtCuNi/CNF@CF monolith [91]. The electroactivity tests of a comparative study carried out on various $\mathrm{Pt}: \mathrm{Cu}: \mathrm{Ni}$ ratios and on Pt/C catalysts showed that the PtCuNi/CNF@CF systems provide the highest activity towards HER, a long-term stability and resistance to metal dissolution in acidic conditions. However, $\mathrm{Pt}_{13} \mathrm{Cu}_{73} \mathrm{Ni}_{14} / \mathrm{CNF} @ \mathrm{CF}$ exhibits the best electrocatalytic performance with the lowest overpotential $\left(70 \mathrm{mV}\right.$ at $5 \mathrm{~mA} \mathrm{~cm}{ }^{-2}$ ). Whereas $\mathrm{Pt}_{42} \mathrm{Cu}_{57} \mathrm{Ni}_{1} / \mathrm{CNF} @ \mathrm{CF}$ displayed the smallest negative potential shifts in the LSV after 2000 cycles and the slowest decay rates after a test period of 1000 seconds in $1 \mathrm{M} \mathrm{H}_{2} \mathrm{SO}_{4}$. The authors indicated that the electronic and synergetic effects could favor the HER kinetics enhancement. They also proposed that the structural features as the location of binder-free PtCuNi NPs in the tips of the carbon nanofiber and the hierarchical porous structure seem to favor the stabilization of PtCuNi NPs and to facilitate the transport of electrons as well as the diffusion of electrolyte, respectively. 
Beneficial effects have been achieved by nitrogen-doped carbon encapsulated ternary PtCoFe alloy (PtCoFe@CN) [93]. The TEM analysis showed that the hybrid PtCoFe@CN nanospheres consisted of nanoparticles encapsulated onto carbon shell. The XRD patterns revealed the presence of (110) and (200) cubic face The kinetic studies carried out in $\mathrm{N}_{2}$-saturated $0.5 \mathrm{M}$ $\mathrm{H}_{2} \mathrm{SO}_{4}$ showed a great decrease of the overpotential at $10 \mathrm{~mA} \mathrm{~cm}$ for the ternary alloy in comparison with bimetallic counterparts $(260 \mathrm{mV}, 94 \mathrm{mV}$ for CoFe@CN and PtCo@CN, respectively.). On electrode free of platinum $(\mathrm{CoFe} @ \mathrm{CN})$, the Tafel slope value was about 110 $\mathrm{mV} \mathrm{dec}{ }^{-1}$.

\subsection{Oxygen Evolution Reaction on Noble Metal (Ru, Ir) oxides}

Several scientists involved in this research field demonstrated experimentally that ruthenium $(\mathrm{Ru})$ and iridium (Ir) materials and their oxides are the most active catalysts for OER in aqueous solution $[105,106]$. However, their activities toward $\mathrm{O}_{2}$ evolution reaction are often different. Compared to iridium metal, ruthenium is the most efficient but it dissolves at potentials where oxygen is evolved while Ir exhibits the best corrosion-resistance ability even in severe electrochemical conditions [107].

\subsubsection{OER on Ruthenium based catalysts}

In the former works, ruthenium corrodes to form metal oxide films on the electrode surface at high anodic potentials by the following reaction (equation 21) [108-110]:

$\mathrm{Ru}+4 \mathrm{H}_{2} \mathrm{O} \rightarrow \mathrm{RuO}_{4}+8 \mathrm{H}^{+}+8 e^{-}$

On the other side, it turned out that heat treatments is necessary to maintain the stability of $\mathrm{RuO}_{\mathrm{x}}$ films. Iwakura et al. $[111,112]$ showed via their study that the heating of hydrous ruthenium dioxide affects considerably the electrical and anodic polarization characteristics of ruthenium dioxide electrodes. The authors revealed that anhydrous $\mathrm{RuO}_{2}$ exhibits a metallic conductivity with resistivity, about $2 \times 10^{-3} \Omega^{-1} \mathrm{~cm}^{-1}$, lower than that of hydrous $\mathrm{RuO}_{2}\left(0.1 \Omega^{-1} \mathrm{~cm}^{-1}\right)$. Additionally, anhydrous $\mathrm{RuO}_{2}$ treated at $450{ }^{\circ} \mathrm{C}$ is the best of all in anodic polarization characteristic as well as corrosion resistance. This latter presents the lowest Tafel slope about $40 \mathrm{mV} \mathrm{dec}^{-1}$ versus $70 \mathrm{mV} \mathrm{dec}^{-1}$ for those treated at high temperature. On the other hand, the examination of potential as a function of time under anodic polarization conditions shows that the potential does not change during the experiment with extreme difficulty to detect the dissolution. Indeed, the dissolution rates determined at $50 \mathrm{~mA} \mathrm{~cm}{ }^{-1}$ was equal to zero $(\mathrm{mg} / \mathrm{h})$ for anhydrous $\mathrm{RuO}_{2}$ treated at $450{ }^{\circ} \mathrm{C}$ and $900{ }^{\circ} \mathrm{C}$. 
From the opposite side, Vukovi et al. [113] showed that the stability is really improved after heat treatment of ruthenium electrode but from an electrocatalytic performance point of view there is a loss. The research team studied the properties of the ruthenium layer electrodeposited on a titanium substrate and the effect of heat treatment on their electrocatalytic performance towards OER. The potentiostatic polarization curves for OER recorded in acid medium on both treated and untreated ruthenium electrodeposited electrode showed a Tafel slope increasing

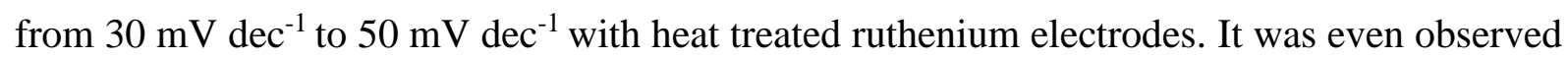
that the main oxidation peak was disappearing after heat treatment. According to the authors this disappearance is probably due to the decrease of the electrode area or to the loss of the electrochemical activity.

Another main characteristic revealed from the studies is the decrease of the current at $1.2 \mathrm{~V}$ vs. SCE for the untreated electrode. Such result highlights the dissolution of ruthenium layer on untreated electrode which causes the decay of current to less than $1 \%$ of its initial value after five hours of polarization at $1.2 \mathrm{~V}$ vs. SCE.

Recently, Kim et al. [114] investigated the electrocatalytic activity and stability of Ru metal and its thermal oxide films for OER in $\mathrm{H}_{2} \mathrm{SO}_{4}$ electrolyte. Ruthenium electrodeposition onto $\mathrm{Ti}$ substrate was carried out in nitrogen saturated $0.5 \mathrm{M} \mathrm{H}_{2} \mathrm{SO}_{4}$ electrolyte at $-0.6 \mathrm{~V}$ vs. SCE for 300 seconds. Afterwards, the Ru/Ti electrodes were heat treated at different temperatures (300, 450 or $600{ }^{\circ} \mathrm{C}$ ) in a furnace under air atmosphere with a temperature ramp of $10^{\circ} \mathrm{C} \mathrm{min}^{-1}$. The changes of morphology, crystal structure and electronic properties after heat treatment were monitored in order to correlate the physico-chemical properties of the elaborated electrodes with their catalytic performances. The main catalyst features can be resumed as follows: XRD patterns showed that the low calcination temperature $\left(300\right.$ and $\left.450{ }^{\circ} \mathrm{C}\right)$ of $\mathrm{Ru} / \mathrm{Ti}$ contributes to the increase of the crystallinity of bulk $\mathrm{Ru}$. In fact, $\mathrm{Ru}$ (101) peak appearing at $44.1^{\circ}$ became sharper after heat treatment. Similar result was obtained after annealing at $600{ }^{\circ} \mathrm{C}$ with some change in the shape of the X-ray diffractogram marked by the appearance of $\mathrm{TiO}_{2}$ peaks. FESEM images revealed the morphological transformation of $\mathrm{Ru} / \mathrm{Ti}$ after heat treatment. The electrodeposited $\mathrm{Ru}$ film changes from smooth and dense surface to a rough one with formation of aggregates very visible with electrode annealed at $450{ }^{\circ} \mathrm{C}$. But heat treatment at $600{ }^{\circ} \mathrm{C}$ led to a hierarchical structure with severe cracking causing the delamination of the Ru oxide films. The catalytic performance tests of electrodeposited and annealed $\mathrm{Ru} / \mathrm{Ti}$ films were carried out in

$0.5 \mathrm{M} \mathrm{H}_{2} \mathrm{SO}_{4}$ electrolyte. Repeated cyclic voltammograms (CVs) (250 cycles) were recorded 
in the potential range of $1.24-1.64 \mathrm{~V}$ vs RHE at a scan rate of $50 \mathrm{mV} \mathrm{s}^{-1}$. For Ru/Ti300 the activation process achieved a maximum current density of $71.4 \mathrm{~mA} \mathrm{~cm}^{-2}$ geo at $1.64 \mathrm{~V}$ vs RHE, after the fortieth cycle. Afterwards, the reactivity rapidly decreases and the CV was no longer observed by reaching $250^{\text {th }}$ cycle. In the case of $\mathrm{Ru} / \mathrm{Ti} 450 \mathrm{film}$, the $\mathrm{CV}$ s current density was lower than that of both electrodeposited $\mathrm{Ru} / \mathrm{Ti}\left(107.6 \mathrm{~mA} \mathrm{~cm}^{-2}{ }_{\text {geo }}\right)$ and $\mathrm{Ru} / \mathrm{Ti}_{300}$ films but regarding the stability, throughout the following cycles, it showed an improvement compared to others. It was not the case for $\mathrm{Ru} / \mathrm{Ti}_{600}$ which showed faster activation process and quick decay. Hence after 250 cycles, the OER activity trend was reported to be $\mathrm{Ru} / \mathrm{Ti}_{450}>\mathrm{Ru} / \mathrm{Ti}_{600}>$ $\mathrm{Ru} / \mathrm{Ti}_{300}>\mathrm{Ru} / \mathrm{Ti}$. FESEM and XPS analysis were used over the course of the cycles in order to examine the activity and stability behavior of each electrode material. According to the authors, the quantity of anhydrous $\mathrm{RuO}_{2}$ and hydrous $\mathrm{RuO}_{2}$ on the surface of oxide films plays a crucial role on the enhancement of the OER activity and stability. Indeed the highest stable oxide film $\left(\mathrm{Ru} / \mathrm{Ti}_{450}\right)$ for OER revealed the lowest atomic composition of hydrous $\mathrm{RuO}_{2}(43.4 \%)$ compared to $\mathrm{Ru} / \mathrm{Ti}_{300}(59.9 \%)$ and $\mathrm{Ru} / \mathrm{Ti}_{600}(54.6 \%)$. Other than, it presents after fortieth cycles a smoothing surface due to the removal of aggregated surface oxides composed of less stable $\mathrm{RuO}_{3}$ and $\mathrm{RuO}_{4}$. And after 250 cycles, $\mathrm{Ru} / \mathrm{Ti}_{450}$ has the highest portion of anhydrous $\mathrm{RuO}_{2}$ (26.6\%) implying the protection of metallic Ru from complete dissolution to maintain the OER current density stable and high as much as possible. Other studies showed that the activity and stability depend strongly on the structure of $\mathrm{Ru}$ oxides (single crystal or polycrystalline). Castelli, P and Trasatti, S. [115] compared the behavior, for oxygen evolution reaction in acid solutions, of well-defined $\mathrm{RuO}_{2}$ (110) single crystal to polycrystalline films. Indeed, the (110) face appears to be much more stable against dissolution than polycrystalline films. Results evidenced it from the decrease of the roughness factors from 2.5 to 1.7 at high overpotential. The Tafel slope values obtained for (110) face and polycrystalline film are $59 \mathrm{mV} \mathrm{dec}^{-1}$ and 40 $\mathrm{mV} \mathrm{dec}{ }^{-1}$, respectively. Thus, the authors suggested that on $\mathrm{RuO}_{2}(110)$ a retarded chemical step, following the first electron transfer step, is involved with formation of $\mathrm{M}^{-\mathrm{OH}^{*}}$ as an intermediate surface complex undergoing some rearrangement. DFT investigations carried out by Rossmeisl et al. [116] aimed to find correlation between the stability of the reaction intermediates over $\mathrm{RuO}_{2}$ (110) surfaces and the oxygen evolution reaction activities. The effect of water surrounding was explored by performing simulations of five water molecules in the unit cell. The structure of intermediates was determined on two different surfaces: one with all bridges and coordinately unsaturated sites (CUS) covered by adsorbents $\left(\mathrm{O}^{*}\right.$ or $\left.\mathrm{OH}^{*}\right)$ or water molecule. The other one is the $\mathrm{O}^{*}$-covered $\mathrm{RuO}_{2}$ (110) surfaces. For the first case, the adsorption energy of water molecules on the CUS sites covered by $\mathrm{O}^{*}$ or $\mathrm{OH}^{*}$, was less than $0.05 \mathrm{eV}$ 
which means that the effect of solvent is negligible. However, on $\mathrm{O}^{*}$-covered $\mathrm{RuO}_{2}(110)$ surfaces, the water splitting starts off from an oxygen vacancy at a CUS site, where water is dissociated forming a hydroxyl group and $\mathrm{H}^{+}+\mathrm{e}^{-}$. Then, a proton is removed leaving $\mathrm{O}^{*}$ on the surface. Another water molecule dissociated on the CUS sites forming $\mathrm{HOO}^{*}$ with $\mathrm{H}^{+}$and $\mathrm{e}^{-}$. And as a final step, one proton is released from $\mathrm{HOO}^{*}$ causing $\mathrm{O}_{2}$ desorption leaving a vacancy at the surface. The calculated values of free energy reveal that all the reaction steps downhill in free energy at potential above $1.6 \mathrm{~V}$ with an overpotential of $0.37 \mathrm{~V}$, thus OER is feasible. The same calculation was performed on $\mathrm{OH}^{*}$-covered $\mathrm{RuO}_{2}$ (110) surfaces. It was found that all the steps downhill in free energy at potential above $1.73 \mathrm{~V}$. However, at such potential only $\mathrm{O}^{*}$ covered $\mathrm{RuO}_{2}$ (110) surface is stable.

Trends in electrocatalytic activity of the OER are affected by the density of defects on the oxide surfaces. For this reason, Danilovic et al. [117] compared the first potential scan of Ru single crystal faces, characterized by well-arranged surface atoms, with Ru-pollycristalline electrode containing ill-defined low and high coordination surface atoms. The results show that $\mathrm{Ru}(0001)$ is less active than Ru-poly for OER meaning that low defect density hinders the activity of single crystals. From a stability point of view, this one was found inversely proportional to the activity. This relationship showed that the stability of oxide surfaces depend strongly on the coordination of surface atoms.

Thus far, the current density of OER for various $\mathrm{RuO}_{2}$ (films or crystals) was considered to evaluate the catalytic performance of the electrocatalysts. This make comparison of catalyst performances challenging since electrodes can have different catalyst mass loadings and different specific surface areas. So, mass/surface -normalized OER are essential to make a detailed activity descriptor (find correlation between activity, morphology and surface structure). $\mathrm{Ru}$ and $\mathrm{RuO}_{2}$ nanoparticles were elaborated by Lee et al. [107] to explore their activities for OER. $\mathrm{RuO}_{2}$ nanoparticles, obtained from annealing $\mathrm{Ru}$ NPs, had rutile structure and characterized by high cristallinity. They exhibit a spherical shape with uniform size and an average particle diameter about $7 \mathrm{~nm}$. The specific and mass activities of rutile- $\mathrm{RuO}_{2}\left(\mathrm{r}-\mathrm{RuO}_{2}\right)$ for OER in $0.1 \mathrm{M} \mathrm{HClO}_{4}$ medium was $\sim 10 \mu \mathrm{A} \mathrm{cm}^{-2}$ and $11 \mathrm{~A} \mathrm{~g}^{-1}$ at an overpotential of 0.25 (1.48 V vs RHE). Paoli et al. [118] synthesized $\mathrm{RuO}_{2}$ nanoparticles by magnetron sputtering method. The electrode material was formed by vacuum deposition of ruthenium nanoparticles having a size between $3-9 \mathrm{~nm}$. All the particles are supposed to be spherical. The specific and mass activities of $\mathrm{RuO}_{2}$ nanoparticles in $0.05 \mathrm{M} \mathrm{H}_{2} \mathrm{SO}_{4}$ medium, having a size of $3 \mathrm{~nm}$, are 0.32 $\mathrm{mA} \mathrm{cm}{ }_{\mathrm{Ru}}^{-2}$ and $0.6 \mathrm{~A} \mathrm{mg}^{-1}$ at $1.48 \mathrm{~V}$ vs RHE, respectively. The TOF was found equal to 0.65 
$\mathrm{s}^{-1}$. Even so, the activity decreases with particle size increasing. The stability of $\mathrm{RuO}_{2}$ nanoparticles was studied by rotating ring disk electrode (RRDE) experiments and was compared to $\mathrm{Ru}$ nanoparticles. The ring measurements display an anodic dissolution of $\mathrm{Ru}$ estimated at $15 \%$ of the total current. This later seems to corrode immediately to $\mathrm{RuO}_{4}$ under OER conditions. However, $\mathrm{RuO}_{2}$ nanoparticles showed more stable behavior with a negligible ring current. These results were evidenced by electrochemical scanning tunneling microscopy (EC-STM), where STM images showed the disappearance of Ru nanoparticles during cyclic voltammetry scan, while $\mathrm{RuO}_{2}$ nanoparticles are maintained [118]. Comparing both works of Paoli et al. [118] and Lee et al. [107], it is obvious that elaboration methods affect considerably the activity and stability of the $\mathrm{RuO}_{2}$. It proves that $\mathrm{RuO}_{2}$ nanoparticles with well-defined shape and small nanoparticle size exhibit more active sites on the terrace (CUS) of $\mathrm{RuO}_{2}$ surface and an optimal compromise in binding between the different intermediates. However, it seems that further improvements in stability are necessary.

Various studies have evidenced the beneficial effect of the mixed oxide in reducing the overpotential of oxygen evolution reaction. The choice of the second oxide is based on its intrinsic properties that influence strongly on the physico-chemical characteristics and electrocatalytic activity of the mixed oxide. Kötz et al. [119] demonstrated that the addition of small amount of $\mathrm{IrO}_{2}(20 \%)$ to $\mathrm{RuO}_{2}$ could decrease to about $4 \%$ of the corrosion rate of the measured value of pure ruthenium oxide. Moreover, an increase of the $\mathrm{O}_{2}$ evolution potential as well as the Tafel slope was obtained when $\mathrm{IrO}_{2}$ content increases. For $\mathrm{Ru}_{0.5} \mathrm{Ir}_{0.5} \mathrm{O}_{2}$, it was found that the alloyed catalyst behave like pure $\mathrm{IrO}_{2}$. The good electrochemical properties of the mixed oxide are determined by a direct interaction of the different components in the bulk by forming a common d-band which ensures the formation of an electrode with homogenous properties and facilitates the electronic charge transfer between the alloy components. As a consequence, $\mathrm{Ru}$-Ir alloying prevents the formation of the corrosive $\mathrm{RuO}_{4}$ so the valence state of $\mathrm{Ru}$ is maintained under VIII. Nevertheless, the number of $\mathrm{Ru}$ active sites for $\mathrm{O}_{2}$ evolution reaction decreases. To further inhibit the anodic corrosion of $\mathrm{Ru}$ cations and to reach a considerable activity, the use of mixed phases of $\mathrm{RuO}_{2}$ and $\mathrm{IrO}_{2}$ containing cobalt have been investigated [120]. González-Huerta et al. [120] performed a DFT calculation in order to find a correlation between the rate determining step and the overpotential decreases. The experimental tests carried out in $0.5 \mathrm{M} \mathrm{H}_{2} \mathrm{SO}_{4}$ revealed that $\mathrm{RuIrCoO}_{x}$ presents the lowest Tafel slopes (68 $\mathrm{mV} \mathrm{dec}{ }^{-1}$ ) compared to its pure counterparts. Other that, the highest stability while $\mathrm{RuO}_{2}$ and $\mathrm{IrO}_{2}$ voltammograms showed a decrease in their current density with time. However, the onset potential for OER has been found between that pure $\mathrm{RuO}_{2}$ and pure $\mathrm{IrO}_{2}$. According to the 
authors, the origin of $\mathrm{RuIrCoO}_{\mathrm{x}}$ activity and stability may arise from the presence of Co oxide. Interestingly, the DFT calculations predicted for this material that an electronic effect facilitates the $\mathrm{OH}$ bond breaking and reduces the overall OER barrier. Another ternary catalyst for example $\operatorname{Ir}_{0.4} \mathrm{Ru}_{0.6} \mathrm{Mo}_{\mathrm{x}} \mathrm{O}_{\mathrm{y}}$, elaborated by the modified Adams' fusion method [121], was found to be promising for OER more than $\operatorname{Ir}_{0.4} \mathrm{Ru}_{0.6} \mathrm{O}_{2}$. An improvement of the single cell performance was also obtained with $\operatorname{Ir}_{0.4} \mathrm{Ru}_{0.6} \mathrm{Mo}_{\mathrm{x}} \mathrm{O}_{\mathrm{y}}$. According to the authors, the enhanced activity can be attributed to the increase of the electrochemical active surface area and to the small particle size [121].

\subsubsection{OER on Iridium based catalysts}

Substitution of $\mathrm{RuO}_{2}$ for $\mathrm{IrO}_{2}$ has stimulated many researchers [40, 122-124] owing to its high corrosion resistance, low overpotential and good activity in polymer electrolyte membrane water electrolyzer / solid polymer electrolyte water electrolyzer (PEMWE/SPEWE). Several studies have been investigating the electrocatalytic activity of nanostructured iridium oxide for OER, in the acidic electrolyte. Most of these studied suggest that structural and morphological properties affect strongly the electrocatalytic activity by influencing the electrochemical active surface area and oxygen adsorption kinetics. Lee et al. [125] elaborated iridium nanodendrites (IrNDs) using tetradecyltrimethyl ammonium bromide (TTAB) as an organic capping agent. HR-TEM images revealed that Ir was dendritic with branches in various directions where particles are $10 \mathrm{~nm}$ in size, contrary to commercial Ir which was in the form of agglomerated nanoparticles. The CV curves of OER showed an intense anodic current density for IrNDs which reflects their high electrocatalytic activity compared to Ir nanoparticles. The XPs analysis confirmed the formation of an anodic $\mathrm{IrO}_{2}$ film on the surface of IrNDs and its presence seems to increase the active facet area available for OER. In order to demonstrate the strong influence of crystallinity and porosity on the electrocatalytic performance and stability of the catalysts, mesoporous $\mathrm{IrO}_{2}$ films have been prepared via soft [126] and hard [127] templating. Both of them showed an enhancement of the electrocatalytic activity and stability for OER, compared to untemplated $\mathrm{IrO}_{2}$. The general trend of their performance confirms that pore templating is an efficient way to control surface catalytic properties by balancing the electrochemical active surface area and the oxygen accessible sites. The efficiency of tubular morphology of $\mathrm{IrO}_{2}$ for OER was tested by $\mathrm{Zhao}$ et al. [128]. $\mathrm{IrO}_{2}$ nanotube $\left(\mathrm{IrO}_{2} \mathrm{NT}\right)$ arrays were fabricated via a novel template deposition and etching strategy. HRTEM along with SEM showed a well-defined tube -like of polycrystalline nature with an average wall thickness of $15 \mathrm{~nm}$. The XPS analysis 
demonstrated that the nanotube arrays of $\mathrm{IrO}_{2}$ are formed. Through this technique the presence of iridium in the $4^{+}$oxidation state was evidenced. It is believed that oxygen is present in the Ir-O-Ir bond or adsorbed as hydroxide on the nanotube surfaces. The electrocatalytic performance of $\mathrm{IrO}_{2} \mathrm{NTs}$ arrays was evaluated by cyclic voltammetry and linear sweep voltammetry (LSV). The obtained results revealed that $\mathrm{IrO}_{2} \mathrm{NTs}$ have a catalytic activity three times higher than that of $\mathrm{IrO}_{2}$ nanoparticles. Indeed, The TOF values estimated at $1.42 \mathrm{~V}$ vs RHE were $3.3 \mathrm{~s}^{-1}$ and $1.21 \mathrm{~s}^{-1}$ for $\mathrm{IrO}_{2}$ nanotube arrays and $\mathrm{IrO}_{2}$ nanoparticles, respectively. However, the onset evolution potential of $\mathrm{IrO}_{2}$ nanotube arrays $(0.99 \mathrm{~V}$ vs $\mathrm{RHE})$ was found slightly lower than that of $\mathrm{IrO}_{2}$ nanoparticles (1.02 V vs RHE). Importantly, the OER current can maintain $83 \%$ of its density even after 100 cycles which was not the case for $\mathrm{IrO}_{2}$ nanoparticles that conserve only $21 \%$ of their initial current values under the same conditions. The higher performance of the catalyst may be related to its preparation method. The authors suggest that the synthesis process provides a perfect architecture integrating advantages of porous structure, dense active sites and easy electron transfer. Recently Badam et al. [129] investigated the electrocatalytic activity and stability of iridium oxide supported on carbon nanotubes $\left(\mathrm{IrO}_{2} / \mathrm{CNT}\right)$. The sample was elaborated via hydrothermal method. From TEM images, the $\mathrm{IrO}_{2}$ nanoparticles were homogenously dispersed onto the substrate with an average particle size of $1.7 \pm 0.3 \mathrm{~nm}$. The small particle size allowed to obtain a very large specific surface area estimated to be $303 \mathrm{~m}^{2} \mathrm{~g}^{-1}$. On the bases of the XRD and XPS investigations, the presence of $\mathrm{IrO}_{2}$ rutile structure and $\mathrm{Ir}^{\mathrm{IV}}$ form were confirmed. The electrocatalytic activity of $\mathrm{IrO}_{2} / \mathrm{CNT}$ was evaluated by LSV in $0.1 \mathrm{M} \mathrm{H}_{2} \mathrm{SO}_{4}$. The catalyst displayed a high current density and a positive shift of the onset potential compared to $\mathrm{IrO}_{2}$ powder [130]. The Tafel slope was found around $60 \mathrm{mV} \mathrm{dec}^{-1}$ and regarding the mass activity and the overpotential the values were estimated of $88 \mathrm{~A} \mathrm{~g}^{-1}$ at $1.48 \mathrm{~V}$ vs RHE and $270 \mathrm{mV}$ at $10 \mathrm{~mA} \mathrm{~cm}^{-2}$, respectively. The long term durability of $\mathrm{IrO}_{2} / \mathrm{CNT}$ was tested by ADT and chronopotentiometry. The obtained voltammograms revealed that the catalyst maintains $80 \%$ of its initial current even after 2500 potential cycles and further it is stable for a period of 3 hours. The high stability for OER is attributed to the strong interaction between $\mathrm{IrO}_{2}$ and substrate that hinders the displacement of the nanoparticles and thereby their agglomeration. This suggestion was supported by TEM images that showed no change of the $\mathrm{IrO}_{2}$ particle sizes after the durability tests which allow the maintaining of a high specific active surface area.

Besides of the high stability and activity of $\mathrm{IrO}_{2}$ as anodic catalysts for OER, its high cost required therefore the elaboration of iridium based catalysts. It seems to be a satisfactory way to reach an optimum activity and stability. Mixed phases of $\mathrm{IrO}_{2}$ with other rutile oxides or inert 
oxide have been widely investigated and showed a significant increase in the catalytic activity and electronic conductivity. For instance, Audichon et al. [131] synthesized an $\mathrm{IrO}_{2}$ coated on commercial ruthenium oxide (IV) nanoparticles catalyst. From TEM images a thin layer of $\mathrm{IrO}_{2}$ covering core $\mathrm{RuO}_{2}$ surface was observed. The core shell structure of $\mathrm{IrO}_{2} @ \mathrm{RuO}_{2} \mathrm{NPs}$ exhibits a high degree of crystallinity with an average crystallite size of $5.7 \mathrm{~nm}$. From the CV measurements, the $\mathrm{IrO}_{2} @ \mathrm{RuO}_{2}$ was found to have the largest number of accessible active sites on the catalyst layer. Indeed, the highest accessible charge $\left(\mathrm{q}^{*}\right.$ outer $)$, which is proportional to the number of active sites, was obtained with $\mathrm{IrO}_{2} @ \mathrm{RuO}_{2}(5.39 \mathrm{mC})$ followed by those obtained for $\mathrm{IrO}_{2}(4.59 \mathrm{mC})$ and $\mathrm{RuO}_{2}(3.28 \mathrm{mC})$. Furthermore, The electrochemical test showed that $\mathrm{IrO}_{2} @ \mathrm{RuO}_{2}$ has the highest current density at $1.5 \mathrm{~V}$ vs. RHE $\left(10.8 \mathrm{~mA} \mathrm{~cm}^{-2}\right)$ with a Tafel slope of $57.8 \mathrm{mV} \mathrm{dec}^{-1}$, i.e the $b$ value is intermediate between that of $\mathrm{RuO}_{2}\left(50 \mathrm{mV} \mathrm{dec}^{-1}\right)$ and $\mathrm{IrO}_{2}$ $\left(60.2 \mathrm{mV} \mathrm{dec}^{-1}\right)$. Such value can be attributed to the adsorption of intermediates involving $\mathrm{OH}$ groups on the electrode surface. The authors suggested that the dissociative water adsorption step is the rate determining step which can occur with two parallel reactions, as follow:

$\mathrm{M}-\mathrm{H}_{2} \mathrm{O} \rightarrow \mathrm{M}-\mathrm{OH}_{a d s}^{*}+\mathrm{H}^{+}+e^{-}$

$M-O H_{a d s}^{*} \rightarrow M-O H_{a d s}$

$\mathrm{M}-\mathrm{OH}^{*}{ }_{\text {ads }}$ and $\mathrm{M}-\mathrm{OH}_{\mathrm{ads}}$ are the intermediate species having the same chemical structure but with different energy states.

Moreover, the coated catalyst showed a considerable stability compared to pure oxide materials. The $\mathrm{CV}$ measurements showed an increase of the current density for $\mathrm{IrO}_{2}$ and $\mathrm{RuO}_{2}$ during the first hundred cycles to tend to stabilize after. On the other hand, the losses in current density for $\mathrm{IrO}_{2} @ \mathrm{RuO}_{2}$ were until the first $50^{\text {th }}$ cycles after that an overlap cycles were obtained and $96.7 \%$ of its active sites are retained even after one thousand cycles. According to the authors, these catalytic activity and stability enhancement of the coated catalyst might be attributed to the good interaction and intimate contact between both oxides, other than the low particle size that promotes the synergetic effects between the two metallic elements.

Conflicting results about the effect of $\mathrm{SnO}_{2}$ addition on the OER activity of $\mathrm{IrO}_{2}$ have been reported. A set of $\operatorname{Ir}_{x}-\mathrm{Sn}_{(1-\mathrm{x})} \mathrm{O}_{2}$ mixed oxide, with different molar proportion of Ir (from 20 to $90 \mathrm{~mol} \%$ ), was prepared by an innovative sol gel method [132]. Their electrocatalytic activities were estimated through the apparent activation energy for OER. The results show that the catalysts performance does not depend on the compositional range of mixed oxide. Importantly, 
the activation energy, estimated at different temperature along the mixed oxide set, was found approximately the same $\left(\sim 12.4 \mathrm{kcal} \mathrm{mol}^{-1}\right)$. The Tafel slope was nearly constant in the 43-55 mV dec ${ }^{-1}$ range for compositions of 20-90 mol \% Ir. The electrochemical oxide formation has been proposed as the mechanistic path. In contrary, De Pauli et al. [133], showed that the current density of OER at $1.49 \mathrm{~V}$ for $\mathrm{IrO}_{2}-\mathrm{SnO}_{2}$ catalysts increases until $20 \mathrm{~mol} \% \mathrm{IrO}_{2}$ and reaches a maximum at $40 \mathrm{~mol} \% \mathrm{IrO}_{2}$. An increase of the OER specific activity, obtained by normalizing the current density to unit surface charge, was obtained with the nominal $\mathrm{IrO}_{2}$ content up to about $40 \%$ but it remains constant for higher percentage. The Tafel slope was nearly 55-60 mV dec ${ }^{-1}$ for nominal composition of 10-100 mol \% $\mathrm{IrO}_{2}$. But, for $\mathrm{IrO}_{2}$ content inferior to $10 \mathrm{~mol} \%$, two Tafel slopes were obtained, one between $60-90 \mathrm{mV} \mathrm{dec}^{-1}$ and the second one higher than $120 \mathrm{mV} \mathrm{dec}{ }^{-1}$. According to the authors, the presence of $\mathrm{SnO}_{2}$ affects the electronic structure of $\mathrm{IrO}_{2}$ which behaves as a semiconductor, at high overpotential. Further tests were carried out with $\mathrm{SnO}_{2}-\mathrm{NbO}_{2}$ mixture promoted $\mathrm{IrO}_{2} / \mathrm{Ti}$ catalysts, for enhancing the oxygen evolution reaction activity and for increasing the stability and durability [134]. Significant changes in the morphological properties of the ternary catalysts were obtained. First of all, TEM images revealed the appearance of cracks on the coated $(\mathrm{IrSnNb}) \mathrm{O}_{2}$ remarkable for the samples with high $\mathrm{IrO}_{2}$ concentration. The crystallite size calculated from XRD characterizations showed that $\mathrm{IrO}_{2}$ rich composition ( $40 \mathrm{~mol} \%$ of $\mathrm{IrO}_{2}$ ) leads to the increase of the particles size of $8-9 \mathrm{~nm}$. Whereas, a decrease of the crystallite size was obtained at lower $\mathrm{IrO}_{2}$ content $(\sim 3 \mathrm{~nm})$. Additionally, the electrochemical activity, represented by a current density at $1.75 \mathrm{~V}$, exhibits two trends of evolution. It seems that when $\mathrm{IrO}_{2}$ content is very high (up to $40 \mathrm{~mol} \%$ ), the samples disclose a good performance similar to that pure $\mathrm{IrO}_{2}$. However, a low iridium oxide content (below $40 \mathrm{~mol} \%$ ) induces a decreasing of $20 \%$ of the current density. In addition, the presence of $\mathrm{SnO}_{2}$ and $\mathrm{NbO}_{2}$ seems to improve the stability of iridium oxide during oxygen evolution reaction. The chronoamperometry tests (CA) carried out at 1.65 $\mathrm{V}$ in $1 \mathrm{M} \mathrm{H}_{2} \mathrm{SO}_{4}$ for 22 hours revealed a marked decay of current (13\% of the initial current density) for both $\left(\operatorname{Ir}_{0.4} \mathrm{Sn}_{0.3} \mathrm{Nb}_{0.3}\right) \mathrm{O}_{2}$ and pure $\mathrm{IrO}_{2}$ during the first 30 minutes. Though, after 1 hour a steady state of current was reached for the ternary catalyst. Such result confirms that the dissolution rate of pure $\mathrm{IrO}_{2}$ is higher than that its counterparts and the ICP results approved this suggestion. Indeed, the analysis of $1 \mathrm{M} \mathrm{H}_{2} \mathrm{SO}_{4}$ after CA experiments evidenced the presence of $0.14 \mathrm{ppm}$ of $\mathrm{Ir}, 0.44 \mathrm{ppm}$ of $\mathrm{Sn}$ and $0.28 \mathrm{ppm}$ of $\mathrm{Nb}$ for $\left(\operatorname{Ir}_{0.4} \mathrm{Sn}_{0.3} \mathrm{Nb}_{0.3}\right) \mathrm{O}_{2}$, while the pure $\mathrm{IrO}_{2}$ shows 0.35 ppm of Ir. 
Interestingly, the elaboration of nanostructured solid solution of $\mathrm{IrO}_{2}, \mathrm{SnO}_{2}$ and $\mathrm{NbO}_{2}$ is an efficient route to minimize the noble metal loading (Ir) and thus lowering the cost of the PEM based water electrolyzers without having a decrease of its electrochemical performance. On the other hand, the improvement of the catalytic activity and stability of the solid solution may be attributed to the strong interaction between $\mathrm{Nb}-\mathrm{O}$ and $\mathrm{Sn}-\mathrm{O}$ bond in comparison with $\mathrm{Ir}-\mathrm{O}$.

\subsection{Conclusion and future trends}

In the present chapter the efficient catalytic materials used for hydrogen production have been reviewed. Pt-based catalysts and $(\mathrm{Ru}, \mathrm{Ir})$ metal oxides are still the most diffused for hydrogen and oxygen evolution reactions, respectively. Different considerations have been taken into account for the fabrication of effective and durable catalysts such as high surface area, low particle size, metal dispersion, electronic structure, etc... Indeed, the combination between surface science and electrochemical characterization allowed the control of the structureactivity relationships. For this reason, anodic and cathodic materials for hydrogen production have different designs: mono- or poly-crystalline, films, supported or unsupported nanoparticles. In particular, pluri-metallic catalysts are widely investigated for both HER and OER due to the good balance between surface structure and performance. However, many of them are unstable (mainly in the case of OER) and their use still expensive under the water splitting conditions. Hence, these issues will motivate future studies to investigate the origin of the active sites and the electron charge transfer process, which help in turn to decrease the cost of hydrogen production and to develop sustainable electrochemical energy conversion as well as storage.

\section{Appendix}

\section{List of acronyms}
ADT Accelerated Degradation Test
$\mathrm{H}_{\mathrm{ads}}$ adsorbed hydrogen
BET Brunauer-Emmett-Teller specific surface area
CF carbon felt
CNF carbon nanofiber
CNT Carbon NanoTubes
CA chronoamperometry
CV cyclic voltammogramm
CUS Coordinately Unsaturated Sites 
DFT Density Functional Theory

EASA electrochemical active surface area

EC-STM Electrochemical Scanning Tunnelling Microscopy

EDX Energy dispersive X-ray spectroscopy

fcc face-centered cubic

FESEM Field Emission Scanning Electron Microscopy

$\mathrm{H}_{\text {upd }} \quad$ underpotentially deposited hydrogen

HER Hydrogen Evolution Reaction

$\mathrm{H}_{\mathrm{opd}}$ overpotentially deposited hydrogen

HRTEM High Resolution Transmission Electron Microscopy

ICP Inductively Coupled Plasma

IrNDs iridium nanodendrites

LSV linear sweep voltammetry

ML monolayers

NCs nanocrystals

NDs nanodentrites

NFs Nanoflowers

NPs nanoparticles

NTs nanotubes

OMC Ordered Mesoporous Carbon

OER Oxygen evolution Reaction

PEM Polymer Electrolyte Membrane

PEMWE Polymer Electrolyte Membrane Water Electrolyzer

Rds rate determining step

rGO reduced graphene oxide

RRDE rotating ring disk electrode

STM Scanning Tunneling Microscopy

STEM Scanning Transmission Electron Microscopy

SiNW Silicon nanowires

SPEWE Solid Polymer Electrolyte Water Electrolyzer

TTAB tetradecyltrimethyl ammonium bromide

TEM Transmission Electron Microscopy

TOF Turnover frequency

XRD X-ray Diffraction 


\section{XPS X-ray Photoelectron Spectroscopy}

\section{List of symbols}

A geometrical surface area

$\mathrm{E}_{\mathrm{a}} \quad$ activation barrier

F $\quad$ Faraday constant

$\mathrm{h}(\mathrm{j})$ polarization resistance

$j \quad$ current density

jo Exchange current density

$\kappa_{\mathrm{c}} \quad$ conductivity of the oxide film.

$\kappa_{\mathrm{s}} \quad$ conductivity of the solution.

$1_{c}$ thickness of the oxide film

$1_{\mathrm{S}}$ distance between the anodic and the cathodic site

lc/אc polarization resistance due to the oxide film

1s/ אs polarization resistance due to the solution resistance

$n \quad$ number of electrons transferred

$N_{A} \quad$ Avogadro constant

$R \quad$ ideal gas constant

$S_{r} \quad$ accessible / electrochemical active surface area of the catalyst

T temperature

$\alpha \quad$ charge transfer coefficient

$\Gamma \quad$ surface or total concentration of catalyst in terms of number of atoms. $\eta \quad$ overpotential

\section{References}

1. Momirlan, M. and T.N. Veziroglu, The properties of hydrogen as fuel tomorrow in sustainable energy system for a cleaner planet. International Journal of Hydrogen Energy, 2005. 30(7): p. 795-802.

2. Cheng, Y. and S.P. Jiang, Advances in electrocatalysts for oxygen evolution reaction of water electrolysis-from metal oxides to carbon nanotubes. Progress in Natural Science: Materials International, 2015. 25(6): p. 545-553.

3. Trasatti, S., Work function, electronegativity, and electrochemical behaviour of metals: III. Electrolytic hydrogen evolution in acid solutions. Journal of Electroanalytical Chemistry and Interfacial Electrochemistry, 1972. 39(1): p. 163-184.

4. Trasatti, S., Electrocatalysis in the anodic evolution of oxygen and chlorine. Electrochimica Acta, 1984. 29(11): p. 1503-1512.

5. Parsons, R., The rate of electrolytic hydrogen evolution and the heat of adsorption of hydrogen. Transactions of the Faraday Society, 1958. 54(0): p. 1053-1063. 
6. Zeng, M. and Y. Li, Recent advances in heterogeneous electrocatalysts for the hydrogen evolution reaction. Journal of Materials Chemistry A, 2015. 3(29): p. 14942-14962.

7. Greeley, J., T.F. Jaramillo, J. Bonde, I. Chorkendorff, and J.K. Nørskov, Computational high-throughput screening of electrocatalytic materials for hydrogen evolution. Nature Materials, 2006. 5: p. 909.

8. Nørskov, J.K., T. Bligaard, A. Logadottir, J.R. Kitchin, J.G. Chen, S. Pandelov, and U. Stimming, Trends in the Exchange Current for Hydrogen Evolution. Journal of The Electrochemical Society, 2005. 152(3): p. J23-J26.

9. Conway, B.E. and G. Jerkiewicz, Relation of energies and coverages of underpotential and overpotential deposited $H$ at Pt and other metals to the 'volcano curve' for cathodic H2 evolution kinetics. Electrochimica Acta, 2000. 45(25): p. 4075-4083.

10. Miles, M.H. and M.A. Thomason, Periodic Variations of Overvoltages for Water Electrolysis in Acid Solutions from Cyclic Voltammetric Studies. Journal of The Electrochemical Society, 1976. 123(10): p. 1459-1461.

11. Sardar, K., E. Petrucco, C.I. Hiley, J.D.B. Sharman, P.P. Wells, A.E. Russell, R.J. Kashtiban, J. Sloan, and R.I. Walton, Water-Splitting Electrocatalysis in Acid Conditions Using Ruthenate-Iridate Pyrochlores. Angewandte Chemie (International Ed. in English), 2014. 53(41): p. 10960-10964.

12. Lodi, G., E. Sivieri, A. De Battisti, and S. Trasatti, Ruthenium dioxide-based film electrodes. Journal of Applied Electrochemistry, 1978. 8(2): p. 135-143.

13. Koper, M.T.M., Thermodynamic theory of multi-electron transfer reactions: Implications for electrocatalysis. Journal of Electroanalytical Chemistry, 2011. 660(2): p. 254-260.

14. Bard, A.J. and L.R. Faulkner, Fundamentals and applications. Electrochemical Methods, 2001. 2: p. 482.

15. Laursen, A.B., S. Kegnaes, S. Dahl, and I. Chorkendorff, Molybdenum sulfides-efficient and viable materials for electro - and photoelectrocatalytic hydrogen evolution. Energy \& Environmental Science, 2012. 5(2): p. 5577-5591.

16. Conway, B.E. and B.V. Tilak, Interfacial processes involving electrocatalytic evolution and oxidation of $H 2$, and the role of chemisorbed $H$. Electrochimica Acta, 2002. 47(22): p. 3571-3594.

17. Seri, O. and B. Siree, The Differentiating Polarization Curve Technique for the Tafel Parameter Estimation. Catalysts, 2017. 7(8).

18. Sheng, W., H.A. Gasteiger, and Y. Shao-Horn, Hydrogen Oxidation and Evolution Reaction Kinetics on Platinum: Acid vs Alkaline Electrolytes. Journal of The Electrochemical Society, 2010. 157(11): p. B1529-B1536.

19. Damjanovic, A., A. Dey, and J.O.M. Bockris, Kinetics of oxygen evolution and dissolution on platinum electrodes. Electrochimica Acta, 1966. 11(7): p. 791-814.

20. Hrussanova, A., E. Guerrini, and S. Trasatti, Thermally prepared Ti/RhOx electrodes IV: O2 evolution in acid solution. Journal of Electroanalytical Chemistry, 2004. 564: p. 151-157.

21. Seri, O., Differentiating approach to the Tafel slope of hydrogen evolution reaction on nickel electrode. Electrochemistry Communications, 2017. 81: p. 150-153.

22. Boudart, M., A. Aldag, J.E. Benson, N.A. Dougharty, and C. Girvin Harkins, On the specific activity of platinum catalysts. Journal of Catalysis, 1966. 6(1): p. 92-99.

23. Boudart, M., Turnover Rates in Heterogeneous Catalysis. Chemical Reviews, 1995. 95(3): p. 661-666.

24. Anantharaj, S., S.R. Ede, K. Sakthikumar, K. Karthick, S. Mishra, and S. Kundu, Recent Trends and Perspectives in Electrochemical Water Splitting with an Emphasis on 
Sulfide, Selenide, and Phosphide Catalysts of Fe, Co, and Ni: A Review. ACS Catalysis, 2016. 6(12): p. 8069-8097.

25. Anantharaj, S., P.E. Karthik, B. Subramanian, and S. Kundu, Pt Nanoparticle Anchored Molecular Self-Assemblies of DNA: An Extremely Stable and Efficient HER Electrocatalyst with Ultralow Pt Content. ACS Catalysis, 2016. 6(7): p. 4660-4672.

26. Anantharaj, S., M. Jayachandran, and S. Kundu, Unprotected and interconnected RuO nano-chain networks: advantages of unprotected surfaces in catalysis and electrocatalysis. Chemical Science, 2016. 7(5): p. 3188-3205.

27. Guo, S.-X., Y. Liu, A.M. Bond, J. Zhang, P. Esakki Karthik, I. Maheshwaran, S. Senthil Kumar, and K.L.N. Phani, Facile electrochemical co-deposition of a graphene-cobalt nanocomposite for highly efficient water oxidation in alkaline media: direct detection of underlying electron transfer reactions under catalytic turnover conditions. Physical Chemistry Chemical Physics, 2014. 16(35): p. 19035-19045.

28. Ma, L., L.R.L. Ting, V. Molinari, C. Giordano, and B.S. Yeo, Efficient hydrogen evolution reaction catalyzed by molybdenum carbide and molybdenum nitride nanocatalysts synthesized via the urea glass route. Journal of Materials Chemistry A, 2015. 3(16): p. 8361-8368.

29. Merki, D., S. Fierro, H. Vrubel, and X. Hu, Amorphous molybdenum sulfide films as catalysts for electrochemical hydrogen production in water. Chemical Science, 2011. 2(7): p. 1262-1267.

30. Chen, Z., D. Cummins, B.N. Reinecke, E. Clark, M.K. Sunkara, and T.F. Jaramillo, Core-shell MoO3-MoS2 Nanowires for Hydrogen Evolution: A Functional Design for Electrocatalytic Materials. Nano Letters, 2011. 11(10): p. 4168-4175.

31. Benck, J.D., Z. Chen, L.Y. Kuritzky, A.J. Forman, and T.F. Jaramillo, Amorphous Molybdenum Sulfide Catalysts for Electrochemical Hydrogen Production: Insights into the Origin of their Catalytic Activity. ACS Catalysis, 2012. 2(9): p. 1916-1923.

32. Kibsgaard, J. and T.F. Jaramillo, Molybdenum Phosphosulfide: An Active, Acid-Stable, Earth-Abundant Catalyst for the Hydrogen Evolution Reaction. Angewandte Chemie International Edition, 2014. 53(52): p. 14433-14437.

33. Bregoli, L.J., The influence of platinum crystallite size on the electrochemical reduction of oxygen in phosphoric acid. Electrochimica Acta, 1978. 23(6): p. 489-492.

34. Gao, M., W. Sheng, Z. Zhuang, Q. Fang, S. Gu, J. Jiang, and Y. Yan, Efficient Water Oxidation Using Nanostructured $\alpha$-Nickel-Hydroxide as an Electrocatalyst. Journal of the American Chemical Society, 2014. 136(19): p. 7077-7084.

35. Fabbri, E., A. Habereder, K. Waltar, R. Kotz, and T.J. Schmidt, Developments and perspectives of oxide-based catalysts for the oxygen evolution reaction. Catalysis Science \& Technology, 2014. 4(11): p. 3800-3821.

36. Sattler, M.L. and P.N. Ross, The surface structure of Pt crystallites supported on carbon black. Ultramicroscopy, 1986. 20(1): p. 21-28.

37. Watt-Smith, M., J. Friedrich, S. Rigby, T. Ralph, and F. Walsh, Determination of the electrochemically active surface area of Pt/C PEM fuel cell electrodes using different adsorbates. Journal of Physics D: Applied Physics, 2008. 41(17): p. 174004.

38. Schalenbach, M., F.D. Speck, M. Ledendecker, O. Kasian, D. Goehl, A.M. Mingers, B. Breitbach, H. Springer, S. Cherevko, and K.J.J. Mayrhofer, Nickel-molybdenum alloy catalysts for the hydrogen evolution reaction: Activity and stability revised. Electrochimica Acta, 2018. 259: p. 1154-1161.

39. Maljusch, A., O. Conradi, S. Hoch, M. Blug, and W. Schuhmann, Advanced Evaluation of the Long-Term Stability of Oxygen Evolution Electrocatalysts. Analytical Chemistry, 2016. 88(15): p. 7597-7602. 
40. McCrory, C.C.L., S. Jung, J.C. Peters, and T.F. Jaramillo, Benchmarking Heterogeneous Electrocatalysts for the Oxygen Evolution Reaction. Journal of the American Chemical Society, 2013. 135(45): p. 16977-16987.

41. Costa, J.D., J.L. Lado, E. Carbó-Argibay, E. Paz, J. Gallo, M.F. Cerqueira, C. Rodríguez-Abreu, K. Kovnir, and Y.V. Kolen'ko, Electrocatalytic Performance and Stability of Nanostructured Fe-Ni Pyrite-Type Diphosphide Catalyst Supported on Carbon Paper. The Journal of Physical Chemistry C, 2016. 120(30): p. 16537-16544.

42. Xu, X., Y. Ge, M. Wang, Z. Zhang, P. Dong, R. Baines, M. Ye, and J. Shen, CobaltDoped FeSe2-RGO as Highly Active and Stable Electrocatalysts for Hydrogen Evolution Reactions. ACS Applied Materials \& Interfaces, 2016. 8(28): p. 1803618042.

43. Will, F.G., Hydrogen Adsorption on Platinum Single Crystal Electrodes: I. Isotherms and Heats of Adsorption. Journal of The Electrochemical Society, 1965. 112(4): p. 451455.

44. Schuldiner, S., M. Rosen, and D.R. Flinn, Comparative Activity of (111), (100), (110), and Polycrystalline Platinum Electrodes in H2-Saturated $1 \mathrm{MH} 2 \mathrm{SO} 4$ under Potentiostatic Control. Journal of The Electrochemical Society, 1970. 117(10): p. 12511259.

45. Kita, H., S. Ye, and Y. Gao, Mass transfer effect in hydrogen evolution reaction on Pt single-crystal electrodes in acid solution. Journal of Electroanalytical Chemistry, 1992. 334(1): p. 351-357.

46. Marković, N.M., B.N. Grgur, and P.N. Ross, Temperature-Dependent Hydrogen Electrochemistry on Platinum Low-Index Single-Crystal Surfaces in Acid Solutions. The Journal of Physical Chemistry B, 1997. 101(27): p. 5405-5413.

47. Barber, J., S. Morin, and B.E. Conway, Specificity of the kinetics of H2 evolution to the structure of single-crystal Pt surfaces, and the relation between opd and upd $H$. Journal of Electroanalytical Chemistry, 1998. 446(1): p. 125-138.

48. Conway, B.E. and G. Jerkiewicz, Nature of electrosorbed $H$ and its relation to metal dependence of catalysis in cathodic $\mathrm{H}_{2}$ evolution. Solid State Ionics, 2002. 150(1): p. 93-103.

49. Chavez, L.O., E. Herrera-Peraza, and Y. Verde-Gomez, Mathematical Modeling of the Hydrogen Evolution Reaction on Pt/C Electrodes Considering Diffusion Effects. Journal of New Materials for Electrochemical Systems, 2010(3): p. 283-287.

50. Strmcnik, D., P.P. Lopes, B. Genorio, V.R. Stamenkovic, and N.M. Markovic, Design principles for hydrogen evolution reaction catalyst materials. Nano Energy, 2016. 29: p. 29-36.

51. Huang, X., Z. Zhao, Y. Chen, E. Zhu, M. Li, X. Duan, and Y. Huang, A rational design of carbon-supported dispersive Pt-based octahedra as efficient oxygen reduction reaction catalysts. Energy \& Environmental Science, 2014. 7(9): p. 2957-2962.

52. Takasu, Y., Y. Fujii, K. Yasuda, Y. Iwanaga, and Y. Matsuda, Electrocatalytic properties of ultrafine platinum particles for hydrogen electrode reaction in an aqueous solution of sulfuric acid. Electrochimica Acta, 1989. 34(3): p. 453-458.

53. Liang, H.P., H.M. Zhang, J.S. Hu, Y.G. Guo, L.J. Wan, and C.L. Bai, Pt Hollow Nanospheres: Facile Synthesis and Enhanced Electrocatalysts. Angewandte Chemie International Edition, 2004. 43(12): p. 1540-1543.

54. Peng, Z. and H. Yang, Designer platinum nanoparticles: Control of shape, composition in alloy, nanostructure and electrocatalytic property. Nano Today, 2009. 4(2): p. 143164. 
55. Chen, S. and A. Kucernak, Electrocatalysis under Conditions of High Mass Transport: Investigation of Hydrogen Oxidation on Single Submicron Pt Particles Supported on Carbon. The Journal of Physical Chemistry B, 2004. 108(37): p. 13984-13994.

56. Sun, Y., Y. Dai, Y. Liu, and S. Chen, A rotating disk electrode study of the particle size effects of Pt for the hydrogen oxidation reaction. Physical Chemistry Chemical Physics, 2012. 14(7): p. 2278-2285.

57. Durst, J., C. Simon, A. Siebel, P.J. Rheinländer, T. Schuler, M. Hanzlik, J. Herranz, F. Hasché, and H.A. Gasteiger, (Invited) Hydrogen Oxidation and Evolution Reaction (HOR/HER) on Pt Electrodes in Acid vs. Alkaline Electrolytes: Mechanism, Activity and Particle Size Effects. ECS Transactions, 2014. 64(3): p. 1069-1080.

58. Zalitis, C.M., A.R. Kucernak, J. Sharman, and E. Wright, Design principles for platinum nanoparticles catalysing electrochemical hydrogen evolution and oxidation reactions: edges are much more active than facets. Journal of Materials Chemistry A, 2017. 5(44): p. 23328-23338.

59. Antoine, O., Y. Bultel, R. Durand, and P. Ozil, Electrocatalysis, diffusion and ohmic drop in PEMFC: Particle size and spatial discrete distribution effects. Electrochimica Acta, 1998. 43(24): p. 3681-3691.

60. Nichols, R.J. and A. Bewick, Spectroscopic identification of the adsorbed intermediate in hydrogen evolution on platinum. Journal of Electroanalytical Chemistry and Interfacial Electrochemistry, 1988. 243(2): p. 445-453.

61. Kunimatsu, K., H. Uchida, M. Osawa, and M. Watanabe, In situ infrared spectroscopic and electrochemical study of hydrogen electro-oxidation on Pt electrode in sulfuric acid. Journal of Electroanalytical Chemistry, 2006. 587(2): p. 299-307.

62. Kunimatsu, K., T. Senzaki, M. Tsushima, and M. Osawa, A combined surface-enhanced infrared and electrochemical kinetics study of hydrogen adsorption and evolution on a Pt electrode. Chemical Physics Letters, 2005. 401(4): p. 451-454.

63. Skúlason, E., V. Tripkovic, M.E. Björketun, S. Gudmundsdóttir, G. Karlberg, J. Rossmeisl, T. Bligaard, H. Jónsson, and J.K. Nørskov, Modeling the Electrochemical Hydrogen Oxidation and Evolution Reactions on the Basis of Density Functional Theory Calculations. The Journal of Physical Chemistry C, 2010. 114(42): p. 1818218197.

64. Yang, F., Q. Zhang, Y. Liu, and S. Chen, A Theoretical Consideration on the Surface Structure and Nanoparticle Size Effects of Pt in Hydrogen Electrocatalysis. The Journal of Physical Chemistry C, 2011. 115(39): p. 19311-19319.

65. Tan, T.L., L.-L. Wang, J. Zhang, D.D. Johnson, and K. Bai, Platinum Nanoparticle During Electrochemical Hydrogen Evolution: Adsorbate Distribution, Active Reaction Species, and Size Effect. ACS Catalysis, 2015. 5(4): p. 2376-2383.

66. Kinoshita, K., Particle Size Effects for Oxygen Reduction on Highly Dispersed Platinum in Acid Electrolytes. Journal of The Electrochemical Society, 1990. 137(3): p. 845-848.

67. Childers, C.L., H. Huang, and C. Korzeniewski, Formaldehyde Yields from Methanol Electrochemical Oxidation on Carbon-Supported Platinum Catalysts. Langmuir, 1999. 15(3): p. 786-789.

68. Du, H., L. Gan, B. Li, P. Wu, Y. Qiu, F. Kang, R. Fu, and Y. Zeng, Influences of Mesopore Size on Oxygen Reduction Reaction Catalysis of Pt/Carbon Aerogels. The Journal of Physical Chemistry C, 2007. 111(5): p. 2040-2043.

69. Knani, S., L. Chirchi, S. Baranton, T.W. Napporn, J.-M. Léger, and A. Ghorbel, A methanol - Tolerant carbon supported Pt-Sn cathode catalysts. International Journal of Hydrogen Energy, 2014. 39(17): p. 9070-9079. 
70. Li, Z.-Y., Z.-1. Liu, J.-C. Liang, C.-W. Xu, and X. Lu, Facile synthesis of Pd-Mn3O4/C as high-efficient electrocatalyst for oxygen evolution reaction. Journal of Materials Chemistry A, 2014. 2(43): p. 18236-18240.

71. Willsau, J. and J. Heitbaum, The influence of Pt-activation on the corrosion of carbon in gas diffusion electrodes-A dems study. Journal of Electroanalytical Chemistry and Interfacial Electrochemistry, 1984. 161(1): p. 93-101.

72. Kalasapurayil Kunhiraman, A., M. Ramasamy, and S. Ramanathan, Efficient hydrogen evolution catalysis triggered by electrochemically anchored platinum nano-islands on functionalized-MWCNT. International Journal of Hydrogen Energy, 2017. 42(15): p. 9881-9891.

73. Xu, G.-R., J.-J. Hui, T. Huang, Y. Chen, and J.-M. Lee, Platinum nanocuboids supported on reduced graphene oxide as efficient electrocatalyst for the hydrogen evolution reaction. Journal of Power Sources, 2015. 285: p. 393-399.

74. Yang, T., M. Du, H. Zhu, M. Zhang, and M. Zou, Immobilization of Pt Nanoparticles in Carbon Nanofibers: Bifunctional Catalyst for Hydrogen Evolution and Electrochemical Sensor. Electrochimica Acta, 2015. 167: p. 48-54.

75. Roy, N., K.T. Leung, and D. Pradhan, Nitrogen Doped Reduced Graphene Oxide Based Pt-TiO2 Nanocomposites for Enhanced Hydrogen Evolution. The Journal of Physical Chemistry C, 2015. 119(33): p. 19117-19125.

76. Khdary, N.H. and M.A. Ghanem, Highly dispersed platinum nanoparticles supported on silica as catalyst for hydrogen production. RSC Advances, 2014. 4(91): p. 5011450122.

77. Kao, W.-H. and T. Kuwana, Electrocatalysis by electrodeposited spherical platinum microparticles dispersed in a polymeric film electrode. Journal of the American Chemical Society, 1984. 106(3): p. 473-476.

78. Kayan, D.B., D. Koçak, and M. İlhan, The activity of PAni-Chitosan composite film decorated with Pt nanoparticles for electrocatalytic hydrogen generation. International Journal of Hydrogen Energy, 2016. 41(25): p. 10522-10529.

79. Chakrabartty, S., C.S. Gopinath, and C.R. Raj, Polymer-based hybrid catalyst of low Pt content for electrochemical hydrogen evolution. International Journal of Hydrogen Energy, 2017. 42(36): p. 22821-22829.

80. Han, J.-H., E. Lee, S. Park, R. Chang, and T.D. Chung, Effect of Nanoporous Structure on Enhanced Electrochemical Reaction. The Journal of Physical Chemistry C, 2010. 114(21): p. 9546-9553.

81. Hussein, H.E.M., H. Amari, and J.V. Macpherson, Electrochemical Synthesis of Nanoporous Platinum Nanoparticles Using Laser Pulse Heating: Application to Methanol Oxidation. ACS Catalysis, 2017. 7(10): p. 7388-7398.

82. Snyder, J., I. McCue, K. Livi, and J. Erlebacher, Structure/Processing/Properties Relationships in Nanoporous Nanoparticles As Applied to Catalysis of the Cathodic Oxygen Reduction Reaction. Journal of the American Chemical Society, 2012. 134(20): p. 8633-8645.

83. Park, S., Y.J. Song, J.-H. Han, H. Boo, and T.D. Chung, Structural and electrochemical features of $3 D$ nanoporous platinum electrodes. Electrochimica Acta, 2010. 55(6): p. 2029-2035.

84. $\mathrm{Xu}, \mathrm{Y}$. and B. Zhang, Recent advances in porous Pt-based nanostructures: synthesis and electrochemical applications. Chemical Society Reviews, 2014. 43(8): p. 24392450.

85. Gangopadhyay, R. and A. De, Conducting Polymer Nanocomposites: A Brief Overview. Chemistry of Materials, 2000. 12(3): p. 608-622. 
86. Pringle Jennifer, M., O. Winther-Jensen, C. Lynam, G. Wallace Gordon, M. Forsyth, and R. MacFarlane Douglas, One-Step Synthesis of Conducting Polymer-Noble Metal Nanoparticle Composites using an Ionic Liquid. Advanced Functional Materials, 2008. 18(14): p. 2031-2040.

87. Bazzaoui, E.A., S. Aeiyach, and P.C. Lacaze, Low potential electropolymerization of thiophene in aqueous perchloric acid. Journal of Electroanalytical Chemistry, 1994. 364(1): p. 63-69.

88. Kitchin, J.R., J.K. Nørskov, M.A. Barteau, and J.G. Chen, Role of Strain and Ligand Effects in the Modification of the Electronic and Chemical Properties of Bimetallic Surfaces. Physical Review Letters, 2004. 93(15): p. 156801.

89. Bernsmeier, D., M. Bernicke, E. Ortel, R. Schmack, J. Polte, and R. Kraehnert, Softtemplated mesoporous RuPt/C coatings with enhanced activity in the hydrogen evolution reaction. Journal of Catalysis, 2017. 355: p. 110-119.

90. Huang, X.-Y., A.-J. Wang, L. Zhang, K.-M. Fang, L.-J. Wu, and J.-J. Feng, Melamineassisted solvothermal synthesis of PtNi nanodentrites as highly efficient and durable electrocatalyst for hydrogen evolution reaction. Journal of Colloid and Interface Science, 2018. 531: p. 578-584.

91. Shen, Y., A.C. Lua, J. Xi, and X. Qiu, Ternary Platinum-Copper-Nickel Nanoparticles Anchored to Hierarchical Carbon Supports as Free-Standing Hydrogen Evolution Electrodes. ACS Applied Materials \& Interfaces, 2016. 8(5): p. 3464-3472.

92. Shen, W., B. Wu, F. Liao, B. Jiang, and M. Shao, Optimizing the hydrogen evolution reaction by shrinking Pt amount in Pt-Ag/SiNW nanocomposites. International Journal of Hydrogen Energy, 2017. 42(22): p. 15024-15030.

93. Chen, J., Y. Yang, J. Su, P. Jiang, G. Xia, and Q. Chen, Enhanced Activity for Hydrogen Evolution Reaction over CoFe Catalysts by Alloying with Small Amount of Pt. ACS Applied Materials \& Interfaces, 2017. 9(4): p. 3596-3601.

94. Liu, Q., Y.-M. He, X. Weng, A.-J. Wang, P.-X. Yuan, K.-M. Fang, and J.-J. Feng, Onepot aqueous fabrication of reduced graphene oxide supported porous PtAg alloy nanoflowers to greatly boost catalytic performances for oxygen reduction and hydrogen evolution. Journal of Colloid and Interface Science, 2018. 513: p. 455-463.

95. Dai, M., L. Song, J.T. LaBelle, and B.D. Vogt, Ordered Mesoporous Carbon Composite Films Containing Cobalt Oxide and Vanadia for Electrochemical Applications. Chemistry of Materials, 2011. 23(11): p. 2869-2878.

96. Antolini, E., Carbon supports for low-temperature fuel cell catalysts. Applied Catalysis B: Environmental, 2009. 88(1): p. 1-24.

97. Auer, E., A. Freund, J. Pietsch, and T. Tacke, Carbons as supports for industrial precious metal catalysts. Applied Catalysis A: General, 1998. 173(2): p. 259-271.

98. Tang, S., G. Sun, J. Qi, S. Sun, J. Guo, Q. Xin, and G.M. Haarberg, Review of New Carbon Materials as Catalyst Supports in Direct Alcohol Fuel Cells. Chinese Journal of Catalysis, 2010. 31(1): p. 12-17.

99. Engstfeld, A.K., S. Brimaud, and R.J. Behm, Potential-Induced Surface Restructuring - The Need for Structural Characterization in Electrocatalysis Research. Angewandte Chemie International Edition, 2014. 53(47): p. 12936-12940.

100. Fu, T., J. Fang, C. Wang, and J. Zhao, Hollow porous nanoparticles with Pt skin on a Ag-Pt alloy structure as a highly active electrocatalyst for the oxygen reduction reaction. Journal of Materials Chemistry A, 2016. 4(22): p. 8803-8811.

101. Li, C. and Y. Yamauchi, Facile solution synthesis of Ag@Pt core-shell nanoparticles with dendritic Pt shells. Physical Chemistry Chemical Physics, 2013. 15(10): p. 34903496. 
102. He, W., X. Wu, J. Liu, K. Zhang, W. Chu, L. Feng, X. Hu, W. Zhou, and S. Xie, Formation of AgPt Alloy Nanoislands via Chemical Etching with Tunable Optical and Catalytic Properties. Langmuir, 2010. 26(6): p. 4443-4448.

103. Liu, H. and J. Yang, Bimetallic Ag-hollow Pt heterodimers via inside-out migration of Ag in core-shell Ag-Pt nanoparticles at elevated temperature. Journal of Materials Chemistry A, 2014. 2(19): p. 7075-7081.

104. Ramírez-Caballero, G.E., Y. Ma, R. Callejas-Tovar, and P.B. Balbuena, Surface segregation and stability of core-shell alloy catalysts for oxygen reduction in acid medium. Physical chemistry chemical physics : PCCP, 2010. 12(9): p. 2209-2218.

105. Trasatti, S., Electrocatalysis by oxides - Attempt at a unifying approach. Journal of Electroanalytical Chemistry and Interfacial Electrochemistry, 1980. 111(1): p. 125-131.

106. Cherevko, S., S. Geiger, O. Kasian, N. Kulyk, J.-P. Grote, A. Savan, B.R. Shrestha, S. Merzlikin, B. Breitbach, A. Ludwig, and K.J.J. Mayrhofer, Oxygen and hydrogen evolution reactions on $\mathrm{Ru}, \mathrm{RuO} 2, \mathrm{Ir}$, and IrO2 thin film electrodes in acidic and alkaline electrolytes: A comparative study on activity and stability. Catalysis Today, 2016. 262 . p. $170-180$.

107. Lee, Y., J. Suntivich, K.J. May, E.E. Perry, and Y. Shao-Horn, Synthesis and Activities of Rutile IrO2 and RuO2 Nanoparticles for Oxygen Evolution in Acid and Alkaline Solutions. The Journal of Physical Chemistry Letters, 2012. 3(3): p. 399-404.

108. Llopis, J., I.M. Tordesillas, and J.M. Alfayate, Anodic corrosion of ruthenium in hydrochloric acid solution. Electrochimica Acta, 1966. 11(6): p. 623-632.

109. Kötz, R., H.J. Lewerenz, and S. Stucki, XPS Studies of Oxygen Evolution on Ru and RuO2 Anodes. Journal of The Electrochemical Society, 1983. 130(4): p. 825-829.

110. Horkans, J. and M.W. Shafer, An Investigation of the Electrochemistry of a Series of Metal Dioxides with Rutile-Type Structure: MoO2, WO 2, ReO2, RuO2, OsO2, and IrO2. Journal of The Electrochemical Society, 1977. 124(8): p. 1202-1207.

111. Iwakura, C., K. Hirao, and H. Tamura, Preparation of ruthenium dioxide electrodes and their anodic polarization characteristics in acidic solutions. Electrochimica Acta, 1977. 22(4): p. 335-340.

112. Tamura, H. and C. Iwakura, Metal oxide anodes for oxygen evolution. International Journal of Hydrogen Energy, 1982. 7(11): p. 857-865.

113. Vuković, M., Oxygen evolution on an electrodeposited ruthenium electrode in acid solution - the effect of thermal treatment. Electrochimica Acta, 1989. 34(2): p. 287291.

114. Kim, J.Y., J. Choi, H.Y. Kim, E. Hwang, H.-J. Kim, S.H. Ahn, and S.-K. Kim, Activity and stability of the oxygen evolution reaction on electrodeposited $R u$ and its thermal oxides. Applied Surface Science, 2015. 359: p. 227-235.

115. Castelli, P., S. Trasatti, F.H. Pollak, and W.E. O'Grady, Single crystals as model electrocatalysts: Oxygen evolution on $\mathrm{RuO} 2$ (110). Journal of Electroanalytical Chemistry and Interfacial Electrochemistry, 1986. 210(1): p. 189-194.

116. Rossmeisl, J., Z.W. Qu, H. Zhu, G.J. Kroes, and J.K. Nørskov, Electrolysis of water on oxide surfaces. Journal of Electroanalytical Chemistry, 2007. 607(1): p. 83-89.

117. Danilovic, N., R. Subbaraman, K.-C. Chang, S.H. Chang, Y.J. Kang, J. Snyder, A.P. Paulikas, D. Strmcnik, Y.-T. Kim, D. Myers, V.R. Stamenkovic, and N.M. Markovic, Activity-Stability Trends for the Oxygen Evolution Reaction on Monometallic Oxides in Acidic Environments. The Journal of Physical Chemistry Letters, 2014. 5(14): p. 24742478.

118. Paoli, E.A., F. Masini, R. Frydendal, D. Deiana, C. Schlaup, M. Malizia, T.W. Hansen, S. Horch, I.E.L. Stephens, and I. Chorkendorff, Oxygen evolution on well-characterized mass-selected $R u$ and $R u O(2)$ nanoparticles †Electronic supplementary information 
(ESI) available. See DOI: 10.1039/c4sc02685c Click here for additional data file. Chemical Science, 2015. 6(1): p. 190-196.

119. Kötz, R. and S. Stucki, Stabilization of RuO2 by IrO2 for anodic oxygen evolution in acid media. Electrochimica Acta, 1986. 31(10): p. 1311-1316.

120. González-Huerta, R.G., G. Ramos-Sánchez, and P.B. Balbuena, Oxygen evolution in Co-doped $\mathrm{RuO} 2$ and IrO2: Experimental and theoretical insights to diminish electrolysis overpotential. Journal of Power Sources, 2014. 268: p. 69-76.

121. Cheng, J., H. Zhang, H. Ma, H. Zhong, and Y. Zou, Preparation of IrO.4Ru0.6MoxOy for oxygen evolution by modified Adams' fusion method. International Journal of Hydrogen Energy, 2009. 34(16): p. 6609-6613.

122. Rasten, E., G. Hagen, and R. Tunold, Electrocatalysis in water electrolysis with solid polymer electrolyte. Electrochimica Acta, 2003. 48(25): p. 3945-3952.

123. Wei, G., Y. Wang, C. Huang, Q. Gao, Z. Wang, and L. Xu, The stability of MEA in SPE water electrolysis for hydrogen production. International Journal of Hydrogen Energy, 2010. 35(9): p. 3951-3957.

124. Pfeifer, V., T.E. Jones, J.J. Velasco Vélez, R. Arrigo, S. Piccinin, M. Hävecker, A. Knop-Gericke, and R. Schlögl, In situ observation of reactive oxygen species forming on oxygen-evolving iridium surfaces. Chemical Science, 2017. 8(3): p. 2143-2149.

125. Lee, W.H. and H. Kim, Oxidized iridium nanodendrites as catalysts for oxygen evolution reactions. Catalysis Communications, 2011. 12(6): p. 408-411.

126. Ortel, E., T. Reier, P. Strasser, and R. Kraehnert, Mesoporous IrO2 Films Templated by PEO-PB-PEO Block-Copolymers: Self-Assembly, Crystallization Behavior, and Electrocatalytic Performance. Chemistry of Materials, 2011. 23(13): p. 3201-3209.

127. Li, G., H. Yu, W. Song, M. Dou, Y. Li, Z. Shao, and B. Yi, A Hard-Template Method for the Preparation of IrO2, and Its Performance in a Solid-Polymer-Electrolyte Water Electrolyzer. ChemSusChem, 2012. 5(5): p. 858-861.

128. Zhao, C., H. Yu, Y. Li, X. Li, L. Ding, and L. Fan, Electrochemical controlled synthesis and characterization of well-aligned IrO2 nanotube arrays with enhanced electrocatalytic activity toward oxygen evolution reaction. Journal of Electroanalytical Chemistry, 2013. 688: p. 269-274.

129. Badam, R., M. Hara, H.-H. Huang, and M. Yoshimura, Synthesis and electrochemical analysis of novel IrO2 nanoparticle catalysts supported on carbon nanotube for oxygen evolution reaction. International Journal of Hydrogen Energy, 2018. 43(39): p. 1809518104.

130. Abbott, D.F., D. Lebedev, K. Waltar, M. Povia, M. Nachtegaal, E. Fabbri, C. Copéret, and T.J. Schmidt, Iridium Oxide for the Oxygen Evolution Reaction: Correlation between Particle Size, Morphology, and the Surface Hydroxo Layer from Operando XAS. Chemistry of Materials, 2016. 28(18): p. 6591-6604.

131. Audichon, T., T.W. Napporn, C. Canaff, C. Morais, C. Comminges, and K.B. Kokoh, IrO2 Coated on $\mathrm{RuO} 2$ as Efficient and Stable Electroactive Nanocatalysts for Electrochemical Water Splitting. The Journal of Physical Chemistry C, 2016. 120(5): p. 2562-2573.

132. Ferro, S., D. Rosestolato, C.A. Martínez-Huitle, and A. De Battisti, On the oxygen evolution reaction at IrO2-SnO2 mixed-oxide electrodes. Electrochimica Acta, 2014. 146: p. 257-261.

133. De Pauli, C.P. and S. Trasatti, Composite materials for electrocatalysis of O2 evolution: $\mathrm{IrO} 2+\mathrm{SnO} 2$ in acid solution. Journal of Electroanalytical Chemistry, 2002. 538-539: p. 145-151.

134. Kadakia, K., M.K. Datta, O.I. Velikokhatnyi, P. Jampani, S.K. Park, P. Saha, J.A. Poston, A. Manivannan, and P.N. Kumta, Novel (Ir,Sn,Nb)O2 anode electrocatalysts 
with reduced noble metal content for PEM based water electrolysis. International Journal of Hydrogen Energy, 2012. 37(4): p. 3001-3013. 